\title{
Working
}

Paper 


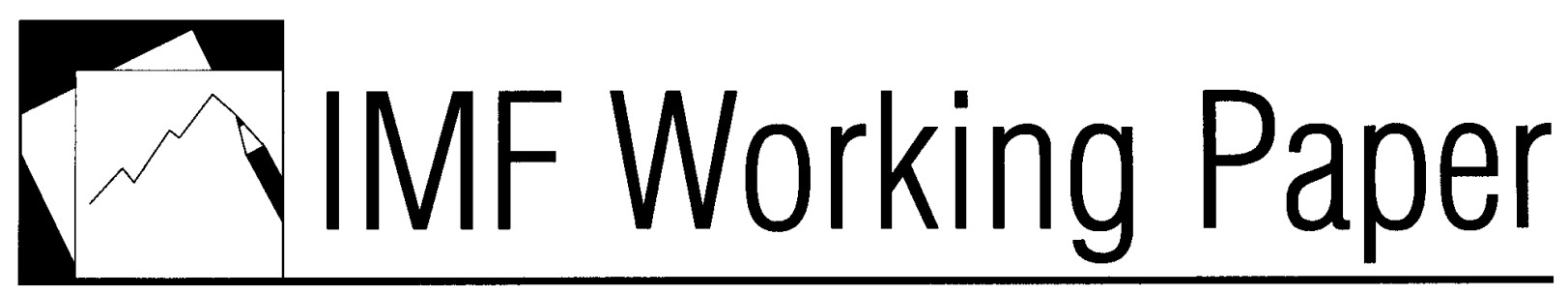

Forecasting and Monetary Policy Analysis in Low-Income Countries: Food and non-Food Inflation in Kenya

Michal Andrle, Andrew Berg, R. Armando Morales, Rafael Portillo and Jan Vlcek

INTERNATIONAL MONETARY FUND 


\title{
IMF Working Paper
}

\author{
Research Department
}

\section{Forecasting and Monetary Policy Analysis in Low-Income Countries: Food and non-Food Inflation in Kenya}

\author{
Michal Andrle, Andrew Berg, R. Armando Morales, Rafael Portillo and Jan Vlcek*
}

Authorized for distribution by Andrew Berg

March 2013

\section{This Working Paper should not be reported as representing the views of the IMF.}

The views expressed in this Working Paper are those of the author(s) and do not necessarily represent those of the IMF, IMF policy or of DFID. Working Papers describe research in progress by the author(s) and are published to elicit comments and to further debate.

\begin{abstract}
We develop a semi-structural new-Keynesian open-economy model, with separate food and nonfood inflation dynamics, for forecasting and monetary policy analysis in low-income countries and apply it to Kenya. We use the model to run several policy-relevant exercises. First, we filter international and Kenyan data (on output, inflation and its components, exchange rates and interest rates) to recover a model-based decomposition of most variables into trends (or potential values) and temporary movements (or gaps) - including for the international and domestic relative price of food. Second, we use the filtration exercise to recover the sequence of domestic and foreign macroeconomic shocks that account for business cycle dynamics in Kenya over the last few years, with a special emphasis on the various factors (international food prices, monetary policy) driving inflation. Third, we perform an out-of-sample forecast to identify where the economy - and therefore policy - was likely headed given the inflationary pressures at the end of our sample (2011Q2). We find that while imported food price shocks have been an important source of inflation, both in 2008 and more recently, accommodating monetary policy has also played a role, most notably through its effect on the nominal exchange rate. The model correctly predicted that a policy tightening was required, although the actual interest rate increase was larger. We discuss implications for the use of model-based policy analysis in low income countries.
\end{abstract}

JEL Classification Numbers: E52, E58, F47, O23

Keywords: Monetary Policy, Forecasting, Food Prices, Kenya, Low-Income Countries Author's E-Mail Address: mandrle@,imf.org ; aberg@,imf.org ; amorales@,imf.org ; rportillo@imf.org; janvlcekatcz@gmail.com

\footnotetext{
* The International Monetary Fund and OGResearch. Email: mandrle@imf.org; aberg@imf.org; amorales@imf.org; rportillo@imf.org; janvlcekatcz@gmail.com. We thank Enrico Berkes for outstanding research assistance. Will Clark also contributed. This working paper is part of a research project on macroeconomic policy in low-income countries supported by the U.K.'s Department for International Development. All errors remain ours.
} 
Contents

Page

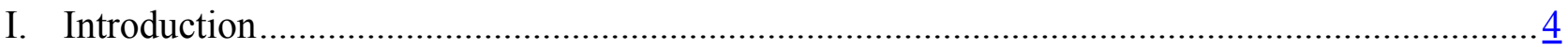

II. Kenya: Inflation Developments and Monetary Policy 2007-2011 _........................................

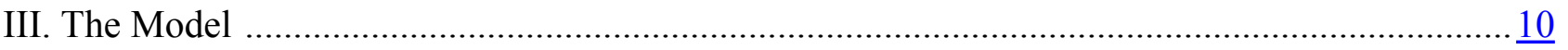

A. Price Indices and Relative Prices ....................................................................................

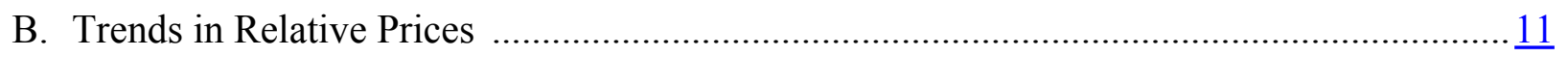

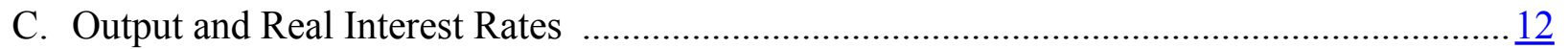

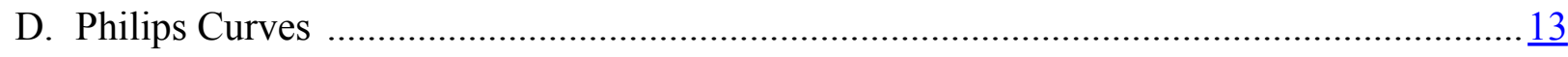

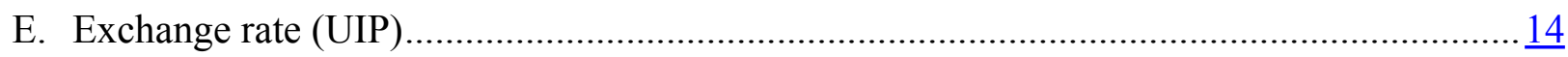

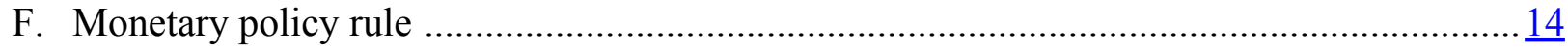

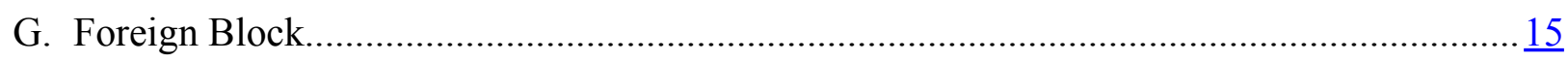

IV. Applying the model for policy analysis in Kenya …….....................................................

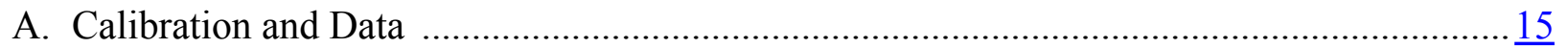

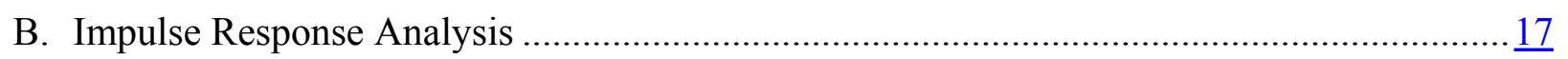

C. Filtering Kenyan Data Through the Model...................................................................

D. A Model-Based Interpretation of Recent History ………………………………………. 22

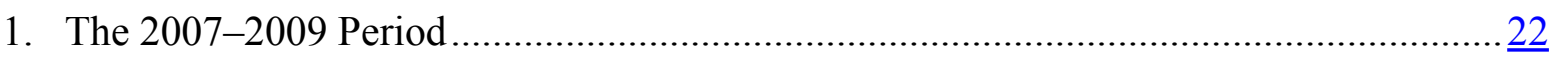

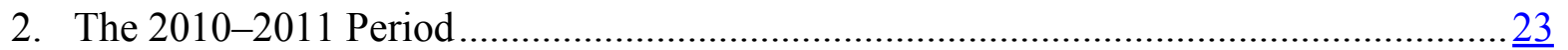

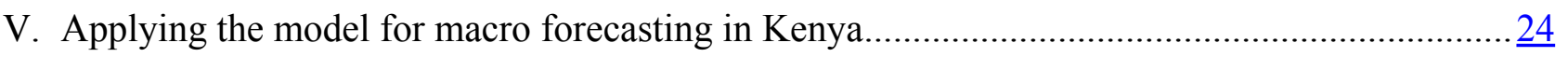

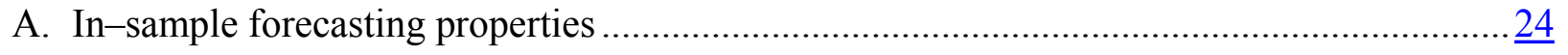

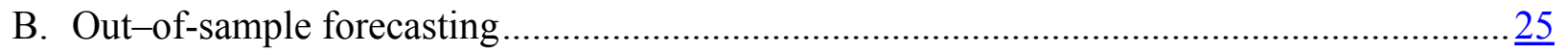

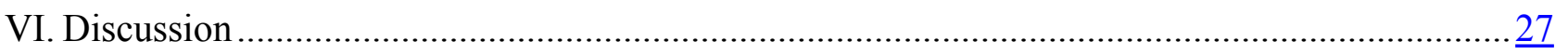

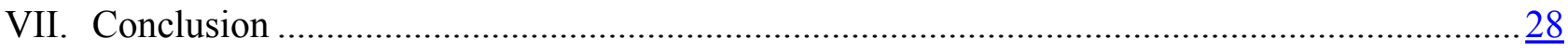

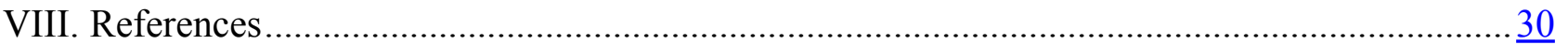

IX. Appendixes

Appendix I. Deriving Phillips Curves from Micro-Foundations .......................................

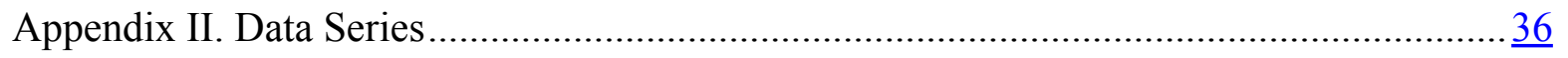

Appendix III. Solving and Using the Model............................................................... $\underline{37}$

1. Solving and Simulating the Model …………………......................................... 37

2. Kalman filter \& Smoother ................................................................................. 37 
X. Tables

Table 1. Calibration ...................................................................................................

Table 2. Calibration (continued)..................................................................................

Table 3. Calibration (continued)......................................................................................

Table 4. In-sample model forecasts (MF) vs. random walk (RW), RMSE ratios ...................

XI. Figures

Figure 1. Food and Non-food Inflation, Kenya................................................................

Figure 2. Domestic and International Food Prices (in US\$) ................................................... 44

Figure 3. Short Term Interest Rates, Kenya ……………………………………………... 45

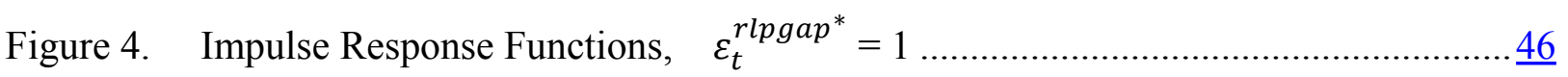

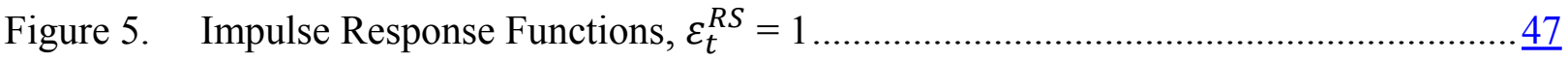

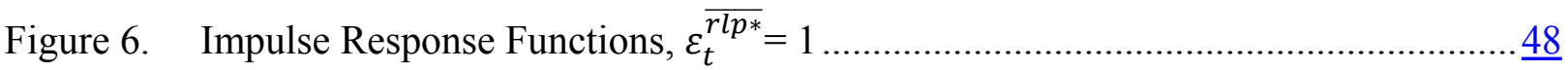

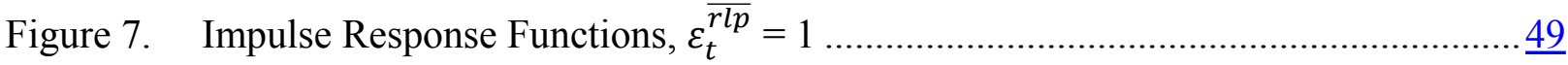

Figure 8. Trend/Gap Decomposition, Relative Prices ........................................................... $\underline{50}$

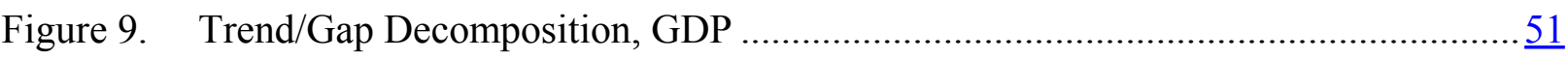

Figure 10. Trend/Gap Decomposition, Real Interest Rates ...................................................

Figure 11. Shock Decomposition, Output Gap ............................................................. $\underline{53}$

Figure 12. Shock Decomposition, Non-Food Inflation ........................................................

Figure 13. Shock Decomposition, Food Inflation................................................................

Figure 14. Shock Decomposition, Headline Inflation .........................................................

Figure 15. Shock Decomposition, Nominal Depreciation .......................................................

Figure 16. Real Marginal Costs Decomposition - Food Price Inflation.................................... $\underline{58}$

Figure 17. Central Bank Rate - Repo Rates ………………...............................................

Figure 18. Impulse Response Functions, 2007-2008 Global Food Crisis................................. 60

Figure 19. Conditioned historical simulations, Selected Variables ............................................

Figure 20. Model Forecast versus Actual Data........................................................................ 62 


\section{INTRODUCTION}

Central banks in many sub-Saharan African (SSA) countries find themselves at a crossroads. During the first half of the 2000s, SSA countries succeeded in re-anchoring inflationary expectations, reducing median inflation in the region from 15 percent in 2000 to 6 percent in 2006. In the context of fiscal-based stabilization efforts, many SSA countries adopted policy regimes centered on targets for reserve and broad money-and considerable management of the exchange rate. ${ }^{2}$ While de facto flexibility was and has always been the norm-money targets are frequently missed in either direction-the adoption of such targets was meant to signal that the central bank was "holding the line", i.e., that stabilization efforts were on track and that fiscal pressures on monetary policy were contained.

More recently however, the region has been buffeted by large external shocks, starting with the first food and fuel crisis of 2007-2008, spillovers from the global financial crisis in 2008-2009 and the latest spike in commodity prices. These shocks have resulted in large swings in inflation. ${ }^{3}$ In some cases the monetary policy response has been erratic. ${ }^{4}$ More generally there has been an acknowledgement among policy makers that existing regimes - with their almost exclusive emphasis on money targets and target misses-have not provided a useful framework for thinking about these shocks, their effects on inflation and the economy, and the role of policy decisions in offsetting or amplifying them. In addition, other factors - structural changes that enhance the role of market signals, increasing instability in money demand, greater exposure to international capital flows-have also called into question the adequacy of existing regimes.

In light of these challenges, some central banks in the region have moved to, or have announced the adoption of, inflation forecast targeting (IFT), a forward-looking regime in which the inflation forecast is the intermediate target of policy, and a short-term interest rate often serves as the operational target. ${ }^{5}$ Under this regime, central bank efforts are focused on understanding (and explaining to the public) why inflation may currently deviate from the target, and determining what policy decisions may be necessary to bring the inflation forecast back in line. While other SSA central banks are not planning to formally adopt IFT in the immediate future, many are interested in adopting certain elements of inflation targeting.

One such element is the development of in-house forecasting and policy analysis systems (FPAS). IFT central banks make ample use of these frameworks to discipline their policy analysis. Specifically, the FPAS framework: (i) collects and helps organize high frequency data; (ii) uses a simple quarterly projection model of the economy that incorporates policymakers' views about the transmission mechanism and the relevant shocks; and (iii)

\footnotetext{
${ }^{2}$ See IMF (2008).

${ }^{3}$ See World Economic Outlook Fall 2011, Chapter 3.

${ }^{4}$ See Benes and others (2012) for a discussion of Zambia's monetary policy responses during the crisis.

${ }^{5}$ With the exception of South Africa, Ghana was the first SSA country to formally adopt inflation targeting in 2007. The Bank of Uganda has also recently announced the adoption of an "Inflation Targeting Lite" regime.
} 
helps develop a consistent, model-based macroeconomic forecast, including with measures of uncertainty and alternative scenarios. ${ }^{6}$

The purpose of this paper (and its companion piece) is to provide a blueprint of an FPAS for low-income countries (LICs), with an application to Kenya. In this paper we extend existing frameworks to include an explicit role for food prices, in light of the importance of these shocks in recent years. In the companion paper we then incorporate monetary aggregates and money targets in the analysis, with an eye on those countries where money targets may continue to play some role in the policy framework. The papers' intended audience is all those concerned with the analysis of monetary policy in low-income countries, especially economists working in the modelling division of central banks in sub-Saharan Africa. The papers are not meant to cover the entire range of exercises and analyses that can be undertaken with such frameworks, but rather to zoom in on some that are relevant for the Kenyan case.

Existing FPAS frameworks are based on new-Keynesian open economy models, which embody the fairly general view that aggregate demand and monetary policy matter for output dynamics in the short run. Unlike their Keynesian predecessors, these models are built on micro-foundations and rational expectations. ${ }^{7}$ At their core, they consist of a forward looking IS equation, a hybrid Phillips curve, a monetary policy rule and an uncovered interest parity equation. ${ }^{8}$ An important feature of these models is the emphasis on gaps in output and the real exchange rate-deviations between observed values and trend or potential components - as drivers of inflation. Considerable effort therefore goes toward distinguishing gaps from trend.

We extend the standard framework by introducing two separate Phillips curves, one for food and one for non-food. The disaggregation requires that special attention be paid to various relative food prices: both the domestic and the international relative price as well as the deviation between the two. It also calls for a careful treatment of trends in these relative prices, which we explicitly undertake here, for two reasons. First, trends in relative prices have implications for the consistency between sectoral inflation rates and the inflation target (toward which headline inflation eventually converges). Second, deviations between relative prices and their trend becomes an important source of inflationary pressures, both sectorally and in the aggregate, as these gaps enter the Phillips curves directly.

The Kenyan case is representative of the challenges SSA countries have faced in recent years. As figure 1 indicates, Kenya experienced large swings in inflation, first increasing to 16 percent in mid 2008, falling back to under 4 percent in mid 2010, only to increase again to almost 20 percent at the end of 2011. While movements in international food prices account for some of these fluctuations, monetary policy may have also played a role, with short term

\footnotetext{
${ }^{6}$ For a thorough discussion of the practical implementation of FPAS frameworks in IFT central banks, see Laxton and others (2009).

${ }^{7}$ See Clarida, Gali and Gertler (1998) and Gali and Monacelli (2002), among many others.

${ }^{8}$ See Berg, Karam and Laxton (2006) for an overview of the standard FPAS model
} 
interest rates falling from 6 percent in 2009 to about 1 percent by early 2011. Disentangling the role of external factors versus the contribution of monetary policy decisions (and other domestic factors) is an important task of monetary policy analysis, a task our FPAS is suited to address.

We use the framework to run a number of exercises. First, we filter selected macroeconomic data from Kenya through the model, in order to recover a model-based decomposition of most series into gap and potential/trend components. The filtration exercise also serves to recover the sequence of macroeconomic shocks that, according to the structure of the model and our own view of recent history, account for business cycle dynamics over the last few years. This allows us to discuss the quantitative significance of various factors (international shocks, monetary policy) in explaining inflation developments. This process is iterative: as we have a prior opinion on the relative importance of various shocks, we repeat the filtration to adjust the calibration of the model until a consistent view of the economy emerges; this iteration also helps us adjust our own views in light of the empirical evidence. Second, we assess the performance of the model with in-sample historical forecasts and the analysis of impulse response functions. Finally, starting from where our data ends (3rd quarter 2011), we perform an out of sample forecast to identify where the economy-and therefore policy — was likely headed given the inflationary pressures at the time.

Our results are the following. First, not surprisingly, we find that imported food shocks have accounted for some of the inflation dynamics in Kenya, both in 2008 but also recently. Domestic food shocks (harvest shocks) were also relevant. We also find that accommodative monetary policy played an important role, both in 2007-2008 and recently. In 2007-2008, the CB experienced "good luck": domestic inflationary pressures were compensated by disinflationary forces associated with the global recession, without a need for tightening. The 2011 inflationary spike was different in that such forces were not present. Interestingly, our exercise indicated that short term interest rates needed to increase, i.e., policy needed to be tightened to offset these inflationary pressures, which is exactly what the central bank of Kenya (CBK) implemented by the end of 2011. The coincidence between the latter response and the model's forecast validates the use of the model for policy analysis in LICs.

We acknowledge that the extension of FPAS-type frameworks to low income countries is not uncontroversial. It is sometimes argued that such countries lack: adequate financial market development, sufficiently strong (or well-understood) monetary policy transmission channels, and various institutional prerequisites, as well as the requisite inflation forecasting ability. These shortcomings, according to this view, would invalidate the application of an FPAS-type framework to LICs, and more generally would call into question the overall effectiveness of monetary policy in stabilizing aggregate demand that is implicit in such frameworks.

We believe that there is still a lot to learn about the monetary transmission mechanism in LICs, but also that there is a lot to gain by applying standard FPAS frameworks to LICs, once these are suitably calibrated to reflect the relative strength of various transmission channels and extended to include LIC-specific shocks. The ability to use such a model to provide a coherent story about the state of the Kenyan economy-and signal the direction of interest 
rate changes - validates our claim. More generally, our experience with Kenya demonstrates that the above challenges represent opportunities to sharpen the analysis and formulation of policy rather than reasons to avoid trying.

Our paper is organized as follows. Section II presents an overview of recent developments in the Kenyan economy. Section III introduces the model. Section IV presents results from the filtering exercise, while Section V discusses forecasting. Section VI discusses some possible reasons behind the monetary policy response in recent years and draws some policy lessons for monetary policy in LICs. Section VII concludes.

\section{Kenya: Inflation Developments and Monetary Policy 2007-2011}

In this section we provide a brief overview of Kenya's economy, its recent inflation history and monetary policy developments.

Kenya is the fourth largest economy in Sub-Saharan Africa (SSA) and the sixth most populated country, with estimated 40 million inhabitants, and a GDP per-capita of US $\$ 1,700$ as of 2011 (in PPP terms). Growth has averaged about 5 percent over the last decade; though it slowed during the global financial crisis. Kenya stands out for its services sector, most notably financial services and telecommunications (with a contribution to GDP of above 60 percent), and for its widespread use of mobile-phone-based payment transfers. 75 percent of the population relies on agriculture for food and income (a large share of which at subsistence levels), which also accounts for 40-50 percent of total exports (tea, coffee and horticulture). The trade balance has been in deficit over the last few years, with remittances, foreign direct investment, and official flows providing the bulk of the financing. Portfolio inflows have been increasing over time, mostly to the stock market (banks, telecommunications and energy), though with a notable slowdown during the global crisis.

Kenya's de jure monetary policy anchor has traditionally been reserve money targeting, although targets on net domestic assets have become more prominent recently (in the context of an IMF program), and the central bank has been paying increasing attention to short-term interest rates. The country maintains a managed float, with foreign exchange rate operations, reflecting in part the role of the $\mathrm{CBK}$ as banker to the government and the magnitude of official FX flows, providing most of the liquidity injections in recent years. It is difficult to identify interventions designed specifically to influence the exchange rate, with considerable volatility in the latter variable.

On the fiscal front, the government's debt lies at about 45 percent of GDP, despite not having benefitted from debt relief as most countries in the region. Instead, about half of the government debt is in domestic currency, thanks to the rapid development of the government securities market. The fiscal deficit has hovered at around 5 percent of GDP in recent years but is consistent with the government's medium term debt strategy, supported by tax revenue equivalent to about 20 percent of GDP (among the highest in SSA). 
Kenya has experienced large swings in inflation in recent years. Headline inflation accelerated from around 3 percent at the beginning of 2007 to 16 percent by mid 2008, and after having fully reversed by mid 2010, climbed again to almost 20 percent by end 2011 . Inflation dynamics were accounted for by both food and non-food (see Figure 1). Although Kenya's share of food in the consumer basket is somewhat below the average for low-income countries ( 38 vs. 50 percent respectively), it is exposed to changes in imported food prices: 40 percent of the total cereal consumption (of about 5 million metric tons, chiefly maize) is imported. This influence can be seen by comparing the Kenyan food price index (measured in dollars) with a price index of international food commodity prices (see Figure 2): the two series display considerable comovement, especially during the food crisis. ${ }^{9}$

Policy challenges were compounded by domestic shocks and the downturn of the global economy in the period 2007-2011, among them:

- A political crisis that followed the December 2007 general elections, resulting in major economic disruptions. During the crisis, over 1,000 people were killed and more than 350,000 (about 1 percent of the population) were displaced. Political instability took a toll on economic activity and exacerbated inflationary pressures in early 2008.

- A drought in the last months of 2008 that aggravated the decline in maize production and increased food insecurity-defined as the size of the population that does not have access to or cannot afford sufficient food-by about 47 percent. The government declared a food emergency for an estimated 10 million Kenyans.

- The significant impact of sharp oil price fluctuations on domestic prices for an oil importer like Kenya.

- The impact of the global financial crisis that initially dampened Kenya's external demand, curtailing export growth, tourism receipts, remittances and private capital flows. Official foreign exchange reserves fell by almost US\$ 800 million (about 20 percent of the stock of reserves) between mid-2008 and early 2009, and Kenya had to borrow from the IMF Exogenous Shock Facility.

It is difficult to characterize the CBKs de facto monetary policy framework. It maintained an inflation target of $5+/-2$ percent. ${ }^{10}$ In terms of instruments, it injected liquidity through foreign exchange purchases and also conducted open market operations. Its reserve money targets have often been missed and subsequently adjusted, so that they in themselves have not dictated monetary policy. ${ }^{11}$ From 2009 through 2011, reserve growth was consistently higher

\footnotetext{
${ }^{9}$ Cointegration between the two series is rejected. Regressing the Kenyan index on the international one (in first differences) generates a pass-through coefficient of 0.36 .

${ }^{10}$ Under the Central Bank of Kenya Act, the Minister of Finance sets the price stability targets of the Government. In practice, the target is set in coordination between the Ministry of Finance and the CBK.

${ }^{11}$ For the purposes of the ongoing Extended Credit Facility (ECF) program with the IMF (in place since January 2011), the CBK also sets a ceiling on net domestic assets (NDA) and a floor for net international reserves (NIR). There is an implied indicative target for reserve money.
} 
than targeted, explained by the CBK in terms of its objective of increasing financial intermediation (through higher broad money growth) and thus supporting economic activity.

The effectiveness, or at least transparency, of monetary policy was hampered by the operational framework in place. The CBK maintained a so-called policy rate meant to signal the stance of policy. This rate was the Central Bank Rate or CBR, at which it stood ready to lend to banks overnight within its standing facility program. In practice the rate was not relevant for the financial system: sizeable injections of liquidity resulted in a large decline in interbank rates, which fell to 1 percent while the CBR stood at 6 percent. Moreover the CBK employed repo and reverse repo operations to manage liquidity, with the rates associated with these operations delinked to the CBR and moving in line with the interbank rate.

Inflation started to accelerate significantly in 2011, reaching almost 19 percent in November. The Shilling depreciated by 15 percent in the six months through November 2011 as inflation expectations deteriorated. In response to these developments, the CBK reduced foreign exchange purchases and suspended the provision of liquidity through reverse repos. As interbank rates started to spike up (see Figure 3), commercial banks began to exploit arbitrage opportunities from the expected depreciation by borrowing from the CBK's overnight discount window and building up foreign exchange positions. In an effort to stem the incipient crisis, the CBK raised the CBR through the second half of 2011 and eventually restricted the use of the discount facility, but without a clear communication strategy, which resulted in even larger increases in the interbank rate.

Facing this instability, and the increase in inflation, the CBK modified its operational framework in September 2011, with a view to making the CBR useful as a signal of policy. It increased the CBR to 18 percent by December 2011 from 6.25 in September. In addition, the CBR became the pivot rate for both repos and reverse repos; i.e., these operations would take place at the CBR rate plus or minus a margin. The overnight rate was set at the CBR rate plus 600 basis points, to eliminate its role as a regular source of funding. Since this reform and policy shift, inflation has been declining steadily, though it remains above the 5 percent target, standing at 13 percent as of April 2012.

In sum, Kenya fits the description of many SSA central banks in IMF (2008): it pursued an inflation objective in the context of a managed float, but with a variety of instruments and intermediate targets, including some-uneven—attention to monetary aggregates. In this paper we choose to simplify by characterizing the stance of policy in terms of a single interest rate. For most of the period, this rate is based on the rates at which open market operations for liquidity provision or withdrawal were actually undertaken (the repo or reverse repo rates). For the most recent period, the CBR serves as an appropriate indicator of the policy stance in terms of interest rates. In a companion paper, we explore the role of money aggregate targets explicitly. Such an analysis may shed light on some of the policy developments during the period under study. However, our understanding is that the CBK authorities and market participants now generally understand the policy stance in terms of the CBR. Given the objective of this paper of providing a practical framework for policy analysis going forward, and the fact that our application of this approach has not revealed major gaps requiring the inclusion of money, we have been satisfied with this approach. 


\section{THE MODEL}

In this section we describe all the equations of the model, i.e., those that describe the interaction of gap terms (business cycle movements) and those that describe movements in potential values or trends.

In terms of general notation, for any given variable $x$ a bar $(\bar{x})$ denotes that variable's trend or potential value. A gap term added to the variable ( $x g a p)$ denotes deviation from trend or potential. A delta $(\Delta)$ in front of the variable indicates changes from one period to the next, except for inflation rates which are denoted with a $\pi$. Finally, an asterisk ${ }^{*}$ denotes a foreign variable.

Before presenting the model it is useful to briefly mention its properties. The model is structural, in that each equation has economic interpretation, and general equilibrium, in that the model's equations jointly determine the dynamics of inflation, output, short-term interest rates and the real exchange rate. It is also stochastic: the system of equations is subject to various shocks, the variance of which can help derive measures of uncertainty in the baseline forecast. Expectations of future variables matter for macroeconomic outcomes and are rational, in the sense that they depend on the model's own forecast. Despite these somewhat-complex features, the core economics embedded in the model are simple: aggregate demand and monetary policy matter for inflation.

One additional comment about the gap/trend decomposition. Just like the new-Keynesian models on which they are based, FPAS models emphasize output and real exchange rate gaps as drivers of inflation. However, unlike more structural/DSGE-type models, FPAS frameworks are agnostic about the structural origin and comovement properties of real trends. As will be shown below the description of trends is limited to the specification of autoregressive processes, based on long-run properties of the data, which greatly simplifies the application of the model.

\section{A. Price Indices and Relative Prices}

We begin by defining price indices and various relative prices. First, the headline price index $\left(p_{t}^{c p i}\right.$, all prices are in logs) is the weighted sum of food $\left(p_{t}^{f}\right)$ and non-food prices $\left(p_{t}^{n f}\right)$ :

$$
\begin{gathered}
p_{t}^{c p i}=w p_{t}^{f}+(1-w) p_{t}^{n f}, \\
\pi_{t}^{c p i}=4\left(p_{t}^{c p i}-p_{t-1}^{c p i}\right)=w \pi_{t}^{f}+(1-w) \pi_{t}^{n f} \\
\pi_{t}^{4, c p i}=p_{t}^{c p i}-p_{t-4}^{c p i}
\end{gathered}
$$

where $w$ is the weight of food, $\pi_{t}$ is the quarterly inflation rate (annualized) and $\pi_{t}^{4}$ is the year-on-year inflation rate. 
The first relative price is the domestic price of food relative to non-food:

$$
r l p_{t}=p_{t}^{f}-p_{t}^{n f} .
$$

The second relative price is the domestic price of food relative to the international price of food measured in local currency:

$$
d e v_{t}=p_{t}^{f}-\left(p_{t}^{* f}+s_{t}\right),
$$

where $p_{t}^{* f}$ is the international price of food (in dollars) and $s_{t}$ is the nominal exchange rate (shillings per dollars). dev $v_{t}$ measures the extent of the deviation between domestic and foreign food prices. As will be show later, whether this deviation creates pressures for domestic food price inflation-in order to catch up with international prices-depends on whether the deviation reflects temporary or long-term factors.

The third relative price is the international price of food relative to the international CPI $\left(p_{t}^{* c p i}\right)$ :

$$
r l p_{t}^{*}=p_{t}^{* f}-p_{t}^{* c p i}
$$

The fourth relative price is the real exchange rate, which is given by the international CPI (measured in domestic currency) minus the domestic CPI:

$$
z_{t}=s_{t}+p_{t}^{* c p i}-p_{t}^{c p i} .
$$

Note that, by construction, all four relative prices are related, as follows:

$$
z_{t}=(1-w) r l p_{t}-r l p_{t}^{*}-d e v_{t} .
$$

The above relation also holds specifically for the gaps and trend components of these relative prices.

For reasons that will become clear later, we also define two alternative real exchange rate measures, a food and a non-food real exchange rate. Each of these relative prices can also be derived using $z_{t}$ and $r l p_{t}$ :

$$
\begin{gathered}
z_{t}^{f}=s_{t}+p_{t}^{* c p i}-p_{t}^{f}=z_{t}-(1-w) r l p_{t} . \\
z_{t}^{n f}=s_{t}+p_{t}^{* c p i}-p_{t}^{n f}=z_{t}+w r l p_{t} .
\end{gathered}
$$

\section{B. Trends in Relative Prices}

All relative prices are decomposed into gap and trend components:

$$
x_{t}=x g a p_{t}+\bar{x}_{t}, \text { for } x=\operatorname{rlp}, r l p^{*}, \operatorname{dev}, z, z^{f}, z^{n f} .
$$

We only need to define stochastic processes for three relative price trends, as trends for the other relative prices will follow from the above relations. We assume first order 
autoregressive processes in first (annualized) differences for the domestic relative price of food $(r l p)$, the international relative price of food $\left(r l p^{*}\right)$ and the real exchange rate $(z)$ :

$$
\begin{gathered}
\Delta \overline{r l p}_{t}=\theta_{r l p} \Delta \overline{r l p}_{t-1}+\left(1-\theta_{r l p}\right) \Delta \overline{r l p}+\varepsilon_{t}^{\overline{r l p}} . \\
\Delta \overline{r l p^{*}}{ }_{t}=\theta_{r l p^{*}} \Delta \overline{r l p}_{t-1}+\left(1-\theta_{r l p^{*}}\right) \Delta \overline{r l p}^{*}+\varepsilon_{t}^{\overline{r l p^{*}}} . \\
\Delta \bar{z}_{t}=\theta_{z} \Delta \bar{z}_{t-1}+\left(1-\theta_{z}\right) \Delta \bar{z}+\varepsilon_{t}^{\bar{z}} .
\end{gathered}
$$

The above specification merits two comments. First, the trend value of $\operatorname{dev}_{t}\left(\overline{\operatorname{dev}}_{t}\right)$ will drift, as implied by the stochastic trends of $r l p_{t}, r l p_{t}^{*}$ and $z_{t}$. This drift implies the long-run value of domestic food prices is unrelated to the long-run value of international food prices: trend changes in international relative food prices $\overline{r l p^{*}}{ }_{t}$ will simply result in an equal and offsetting increase in $\overline{d e v}_{t}$, without any implication for trend changes in domestic relative food prices $\overline{r l p}_{t}$. This is a stronger assumption than lack of cointegration. While this disconnect may seem extreme, it only applies to long-run movements in relative prices and not to gap movements, which — as we will see-account for much of the dynamics in international food prices in the last few years. As will be shown below, it is also based on the observed trend movements in $d e v_{t}$.

Second, the existence of relative price trends has implications for the inflation rates of certain price indices, even if the inflation rate for the headline index is (eventually) determined by the inflation objective. As the relative price of food is either growing or decaying along a stochastic trend (depending on the sign of $\Delta \overline{r l p} p_{t}$ ), nominal food prices will tend to grow at a different rate than non-food prices. Specifically, for any time-varying inflation objective $\bar{\pi}_{t}$, implicit targets for food and non-food inflation must be as follows:

$$
\bar{\pi}_{t}^{f}=\bar{\pi}_{t}+(1-w) \Delta \overline{r l p}_{t}, \quad \bar{\pi}_{t}^{n f}=\bar{\pi}_{t}-w \Delta \overline{r l p}_{t}
$$

In addition, the long-run (annualized) nominal rate of depreciation must be consistent with the process for trend real exchange rates and domestic and foreign inflation targets:

$$
\Delta \bar{s}_{t}=\Delta \bar{z}_{t}+\bar{\pi}_{t}-\bar{\pi}^{*}
$$

\section{Output and Real Interest Rates}

Quarterly (non-agricultural) output is divided into its gap and potential components,

$$
y_{t}=\bar{y}_{t}+\operatorname{ygap}_{t}
$$

where potential output follows a random walk with time-varying drift $g_{t}$ :

$$
\Delta \bar{y}_{t}=g_{t}+\varepsilon_{t}^{\bar{y}}, \quad g_{t}=\tau_{g} \bar{g}+\left(1-\tau_{g}\right) g_{t-1}+\varepsilon_{t}^{g} .
$$

Thus there can be both i.i.d. and persistent shocks to the growth rate, which allows for more flexibility in matching the data. The output gap is given by a hybrid IS curve. It depends on 
real monetary conditions $(r m c)$ and foreign demand $\left(\right.$ ygap $\left.^{*}\right)$, as well as past and future output gaps:

$$
\operatorname{ygap}_{t}=\beta_{1}{y g a p_{t-1}}+\beta_{2} E_{t}\left(\operatorname{ygap}_{t+1}\right)-\beta_{3} r m c_{t-1}+\beta_{5} y g a p_{t}^{*}+\varepsilon_{t}^{y g a p} .
$$

Real monetary conditions are composed of the real interest rate gap ( $r$ rgap) - the difference between actual real interest rates $\left(r s_{t}-E_{t}\left(\pi_{t+1}^{c p i}\right)\right)$ and neutral real interest rates $\left(\overline{r r}_{t}\right)$ - and the real exchange rate gap:

$$
r m c_{t}=\left(1-\beta_{4}\right) \operatorname{rrgap}_{t}+\beta_{4}\left(-z g a p_{t}\right)
$$

Note that neutral rates follow an AR(1) process:

$$
\overline{r r}_{t}=\rho_{\overline{r r}} \overline{r r}_{t-1}+\left(1-\rho_{\overline{r r}}\right) \overline{r r}+\varepsilon_{t}^{\overline{r r}}
$$

\section{Philips Curves}

We introduce two Philips curve, one for non-food prices and one for food prices. As described in Appendix A, both can be derived from micro-foundations. The non-food Philips curve is of the form:

$\pi_{t}^{n f}-\bar{\pi}_{t}^{n f}=\lambda_{1}\left(E_{t}\left(\pi_{t+1}^{n f}\right)-\bar{\pi}_{t}^{n f}\right)+\left(1-\lambda_{1}-\lambda_{2}\right)\left(\pi_{t-1}^{n f}-\bar{\pi}_{t}^{n f}\right)+\lambda_{2}\left(\pi_{n f, t}^{i m p}-\bar{\pi}_{t}^{i m p}\right)+\lambda_{3} r m c_{t}^{n f}+\varepsilon_{t}^{\pi n f}$,

where

$$
\pi_{t}^{i m p}=\pi_{t}^{* c p i}+\Delta s_{t}, \quad \bar{\pi}_{t}^{i m p}=\bar{\pi}_{t}^{* c p i}+\Delta \bar{s}_{t}
$$

and

$$
r m c_{t}^{n f}=\lambda_{4} \text { gap }_{t}+\left(1-\lambda_{4}\right) z^{n f} g a p_{t},
$$

This specification allows temporary changes in imported inflation to have a direct effect on non-food inflation, as captured by the term $\lambda_{2}\left(\pi_{n f, t}^{i m p}-\bar{\pi}_{t}^{i m p}\right)$. It also makes non-food inflation sensitive to expected future and lagged changes of itself, as well as changes in real marginal costs in the non-food sector $\left(r m c_{t}^{n f}\right)$. These are given by a weighted sum of the domestic output gap and the real exchange rate gap in terms of food prices. ${ }^{12}$

The Philips curve for food prices has a similar structure:

$\pi_{t}^{f}-\bar{\pi}_{t}^{f}=b_{1}\left(E_{t}\left(\pi_{t+1}^{f}\right)-\bar{\pi}_{t}^{f}\right)+\left(1-b_{1}-b_{2}\right)\left(\pi_{t-1}^{f}-\bar{\pi}_{t}^{f}\right)+b_{2}\left(\pi^{i m p}-\bar{\pi}_{t}^{i m p}\right)+b_{3} r m c_{t}^{f}+\varepsilon_{t}^{\pi f}$,

where

$$
r m c_{t}^{f}=\left(1-b_{4}-b_{5}\right) y g a p_{t}+b_{4} z^{f} g a p_{t}-b_{5} \text { devgap } .
$$

\footnotetext{
${ }^{12}$ As shown in the appendix, this specification can be derived from microfoundations by assuming that the production of non-food requires a domestic input, e.g., labor, and imported goods. In this case, changes in the domestic cost of production are captured by changes in the output gap, while changes in the imported cost are represented by the real exchange rate gap. Note that, in two sector models, what is inflationary in each sector is not the real exchange rate gap per se but the cost of imported goods relative to prices in that sector, which is why $z^{n f}$ gap $_{t}$ enters the equation and not $z g a p_{t}$.
} 
In addition to potentially different calibrations, the main difference relative to non-food inflation is that real marginal costs also depend on temporary deviations between domestic and international food prices $\left(\right.$ devgap $\left._{t}\right)$. This extra term implies that temporary increases in international food prices will be inflationary, as they open a gap relative to domestic food prices that will be closed (in part) by increases in domestic food prices. ${ }^{13}$

\section{E. Exchange rate (UIP)}

We assume that uncovered interest parity (UIP) holds:

$$
4\left(z g a p_{t}-z g a p_{t}^{e}\right)=-\left(\operatorname{rrgap}_{t}-\operatorname{rrgap}_{t}^{*}\right)+\operatorname{prem}_{t}+\varepsilon_{t}^{s},
$$

where prem $_{t}$ measures persistent movements in the risk premium associated with holding domestic currency, which follows an $\mathrm{AR}(1)$ process with coefficient $\rho_{\text {prem }}$, and $\varepsilon_{t}^{s}$ measure one-time errors in exchange rate valuation. Real exchange rate expectations are allowed to deviate temporarily from rational expectations:

$$
z g a p_{t}^{e}=\phi E_{t}\left(z g a p_{t+1}\right)+(1-\phi) z g a p_{t-1}
$$

\section{F. Monetary policy rule}

We assume that the central bank moves the interest rate in response to endogenous developments in the economy, as follows:

$$
r s_{t}=\gamma_{1} r s_{t-1}+\left(1-\gamma_{1}\right)\left[\overline{r r}_{t}+\bar{\pi}_{t+1}+\gamma_{2}\left(\pi_{t+4}^{4, c p i}-\bar{\pi}_{t+4}^{c p i}\right)+\gamma_{3} \text { ygap }_{t}+\gamma_{4} \Delta \operatorname{sgap}_{t}\right]+\varepsilon_{t}^{r s} .
$$

The central bank also specifies a stochastic process for its inflation target:

$$
\bar{\pi}_{t}=\rho_{\bar{\pi}} \bar{\pi}_{t-1}+\left(1-\rho_{\bar{\pi}}\right) \bar{\pi}+\varepsilon_{t}^{\bar{\pi}}
$$

While this specification may appear surprising — why would the central bank subject its inflation target to persistent fluctuations?-it is meant to capture relatively low-frequency movements in inflation. These movements tend to reflect changes in the central bank's willingness to tolerate certain levels of inflation and have been proven to capture an important element of inflation dynamics in developed and emerging markets. ${ }^{14}$

\footnotetext{
${ }^{13}$ As proved in the appendix, this additional term is microfounded by assuming that the production of the domestic food basket also requires imported food, in addition to domestic labor and imported non-food items.
}

${ }^{14}$ See Smets and Wouters (2003) and Ireland (2007), among others. 


\section{G. Foreign Block}

The dynamics of the model are complete with the the foreign block, a set of six equations that describes the comovement of external variables:

$$
\begin{gathered}
\operatorname{ygap}_{t}^{*}=\beta_{1}^{*} \operatorname{ygap}_{t-1}^{*}+\beta_{2}^{*} \operatorname{ygap}_{t+1}^{*}-\beta_{3}^{*} \operatorname{rrgap}_{t-1}^{*}+\varepsilon_{t}^{\text {ygap }}, \\
\pi_{t}^{* c p i}=\lambda_{1}^{*} \pi_{t+1}^{* c p i}+\left(1-\lambda_{1}^{*}\right) \pi_{t-1}^{* c p i}+\lambda_{2}^{*} \operatorname{ygap}_{t}^{*}+\varepsilon_{t}^{\pi^{*}}, \\
r s_{t}^{*}=\gamma_{1}^{*} r s_{t-1}^{*}+\left(1-\gamma_{1}^{*}\right)\left[\overline{r r}_{t}^{*}+\bar{\pi}^{*}+\gamma_{2}^{*}\left(\pi_{t+4}^{4, * c p i}-\bar{\pi}^{* c p i}\right)+\gamma_{3}^{*} y g a p_{t}^{*}\right]+\varepsilon_{t}^{R S^{*}}, \\
r l p g a p_{t}^{*}=\rho_{f^{*}} r l p g a p_{t-1}^{*}+\varepsilon_{t}^{r l p^{*}}, \\
\overline{r r_{t}^{*}}=\rho_{r r^{*}} \overline{r r}_{t-1}^{*}+\left(1-\rho_{r r^{*}}\right) \overline{r r}^{*}+\varepsilon_{t}^{r r^{*}},
\end{gathered}
$$

and the process for the trend in the international relative price of food described earlier. Note that international food inflation is given by $\pi_{t}^{* f}=\pi_{t}^{* c p i}+\Delta r l p_{t}^{*}$.

\section{APPLying The MOdel FOR POLICY ANALYSis In KenYa}

Having described the model, we now present various model-based exercises for Kenya. We begin by describing the calibration and our data set. We then provide impulse response functions for selected shocks. We describe the filtration exercise, with an emphasis on two related issues: the decomposition of macro-variables into their trend and gap components, and the historical decomposition of recent business-cycle dynamics in Kenya by the relevant shocks.

\section{A. Calibration and Data}

\section{Calibration}

We present the calibration in tables 1-3. Our choice is guided by the following principles. First, some of the parameters of the model (average growth rates of relative prices and output, real interest rates, average inflation target) reflect Kenyan averages or, in the case of the inflation target, the explicit objective of the central bank.

Other parameters reflect our views about structural features of the Kenyan economy. In the IS curve, the relatively large backward-looking term and small forward-looking term reflect our view that expectations of future developments play a relatively small role in output dynamics. The small sensitivity of output to interest rates (given by $\beta_{3}\left(1-\beta_{4}\right)=0.06$ ) is consistent with the view that the interest rate channel is likely to be small in LICs (see Prachi and others (2011)), while the relative importance of the real exchange rate gap in $r m c$ indicates the exchange rate channel is relatively stronger.

In the case of the two Phillips curves, non-food inflation is more sensitive to the output gap, with the sensitivity given by $\lambda_{3} \lambda_{4}=0.1$, than food inflation, with the sensitivity given by 
$b_{3}\left(1-b_{4}-b_{5}\right)=0.02$. The same holds regarding sensitivity to the real exchange rate: it equals $\lambda_{3}\left(1-\lambda_{4}\right)=0.1$ in the non-food sector but only $b_{3} b_{4}=0.04$ in the food sector. On the other hand, food inflation is quite sensitive to temporary gaps between international and domestic food prices $\left(\right.$ devgap $\left._{t}\right)$ : a 1 percent widening of the gap-ignoring expectations of future values of devgap - results in an immediate 0.07 percent increase in food prices. The effect is twice as large (0.13) once expectations about future gaps are incorporated into current prices.

The calibration of the monetary policy rule is relatively dovish, with large smoothing of interest rates and a relatively small response to increases in expected inflation. The calibration also allows for some response to nominal exchange rate movements (an important issue in LICs) but no response to the output gap. The calibration for the rest of the world is taken from applications of similar gap models to the US economy.

Finally, the last set of parameters are calibrated based on the model's ability to deliver plausible interpretations of recent macro dynamics. The parameters that fall in this category are primarily the AR coefficients of most exogenous variables, as well as the variances of the shocks which are listed in Table 3. As is explained in the appendix, the filtration exercise depends on the relative variance of the shocks, since there are more shocks than observables, so the choice of these as well as the AR coefficients help determine the model's account of Kenya's business cycle. For example, if shocks to the trend real exchange rate are considerably more volatile than temporary shocks to the risk premium, then the model will interpret most movements in the real exchange rate as reflecting trend movements rather than gap movements. To pin down these parameter values, we start with an initial calibration, assess the model-based decomposition of the data, and iterate until the model-based story looks plausible. ${ }^{15}$

\section{Data}

The data is described in appendix II. The data is of mixed frequency, and goes from the beginning of 2000 to 2011 . Two series are worth discussing in some detail. The short term interest rate used in the model—monthly series, averaged into quarters-differs from the CBK policy rate, since the latter did not reflect the true stance of monetary policy for reasons discussed in Section II. Instead, we choose the rate that best captures the policy stance. From 2000:1 to 2009:1, and from 20011:5 to 2011:6, we use the repo rate as the central bank was mainly withdrawing liquidity from the money market. From 2009:3 to 2011:4 we use the reverse repo rate since the central bank was mainly injecting liquidity. In 2009:2 we used the average of the two as the central bank was engaging in both operations through the month.

\footnotetext{
${ }^{15}$ It is feasible to estimate the model through Bayesian methods (as for example in Berg, Portillo, and Unsal (2010) for a similar model). However, for operational purposes the iterative process is preferable, at least at first. It helps the operator understand the mechanisms of the model and in particular the mapping between calibrations and the interpretation of history. It also allows the operator to embody views of the transmission mechanism derived from other sources, such as the judgment of policymakers. And it avoids the danger of overfitting, in particular of attempting to fit episodes when the operator knows (or should know) that there really were large unexpected and un-modeled events, e.g. fiscal shocks, movements in the risk premium from global events, or droughts or riots that temporarily drove food prices.
} 
The second series of interest is the CPI series and its components. There have been various changes in methodology in the construction of price indices in Kenya. Previous CPI inflation series suffered from upward biases, especially in food price infation, in part reflecting the use of a chained arithmetic mean formula (the "Carli" index). The Kenya National Bureau of Statistics switched to a geometric mean formula in 2009, for both food and non-food prices, and retroactively revised the aggregate CPI index (but not the subindexes) up to 2005. To construct a consistent series that would go back to the beginning of our sample, we estimated a bias coefficient from the period where the alternative indices (from the two methodologies) overlap and applied the correction to the older series.

\section{B. Impulse Response Analysis}

We begin our assessment of the model by analyzing how a one percent temporary increase in international relative food prices $\left(\varepsilon_{t}^{r l p g a p^{*}}=1\right)$ affects Kenyan inflation, according to various specifications of the model. The purpose of this exercise is to highlight various aspects of the transmission mechanism.

Figure 4 plots impulse responses for international food price inflation as well as domestic food and CPI inflation (all presented on a year-on-year (YoY) basis) for two cases. Results are presented in deviations, i.e., movements in inflation rates above or below their long-run value. By construction, temporary changes to international relative food prices have very short-lived effects on international food inflation, since they result in one time increases in the food price level, which then declines over time. This is reflected in the large drop in YoY international food price inflation after four quarters. However, the effect on domestic inflation is longer-lived, since it takes longer for the increase to be (incompletely) passed on to domestic food prices.

In the first case (left quadrant), we assume that monetary policy does not respond and that the nominal exchange rate does not depreciate. ${ }^{16}$ The increase in inflation can be thought of as the first-round effect of shocks to international food prices. In this case, the shock has a large effect on food inflation but no effect on non-food, so the impact on headline is given by the weight of food in the CPI. In the second case (right quadrant), we allow for monetary policy to respond, in which case the central bank raises interest rates as inflation increases. This policy tightening leads to an incipient decline in the output gap, which, all else equal, creates pressures for both non-food and food inflation to decrease. In addition, the increases in interest rates results in a temporary appreciation of the currency, which also reduces inflation by reducing production costs in both sectors. The increase in inflation is therefore smaller.

Note that the direct effect of monetary policy can also be analyzed with a monetary policy shock $\left(\varepsilon_{t}^{R S}=1\right)$, shown in Figure 5. Consistent with the previous discussion, the shock

\footnotetext{
${ }^{16}$ To generate this scenario, we simulate a subset of the model where the output gap is always set to zero and the nominal interest rate stays constant, in which case the nominal exchange rate-through uncovered interest parity - does not depreciate. As actual real interest rates are declining, this exercise implicitly assumes a decrease in equilibrium real interest rates to maintain the output gap closed.
} 
results in an increase in the output gap, a decline in both components of inflation and a nominal and real depreciation.

Figure 6 shows the effects of an increase in the trend component of international relative food prices $\left(\varepsilon_{t}^{r^{*}{ }^{*}}=1\right)$. In this case, the increase in international food inflation is more persistent, but as described in the model section there is no effect on domestic food and headline inflation, regardless of the monetary policy response or the structure of the economy.

In sum, these experiments show that in our model some shocks to international food prices have inflationary effects and some do not. In the former, we have distinguished a direct effect operating through the structure of the food sector: the exposure to international food prices and the parameters of the Phillips curve. We have also analyzed an indirect effect related to the monetary policy response, which in this case mutes the impact on inflation.

A similar result applies to the other shocks in the model, which we will not discuss in their entirety for the sake of brevity. All non-trend shocks will have an effect on inflation since they affect gap terms, and the monetary policy response will play a role in the propagation of the shock. ${ }^{17}$ Shocks to trend components are not inflationary, with two qualifications. The first qualification is a positive shock to the trend component of the domestic relative price of food $\left(\varepsilon_{t}^{\overline{r l p}}=1\right)$, shown in Figure 7 . In this case, there would be an increase in the food inflation rate, a decrease in non-food inflation rate, but no change in the headline inflation rate (and no monetary policy response). The second exception concerns a shock to equilibrium real interest rates ( $\varepsilon_{t}^{\overline{r r}}$, not shown), which would have an impact on economic activity and inflation because of the slow adjustment in the monetary policy rule. Actual real interest rates would not keep up with equilibrium rates, thus opening a gap in real monetary conditions.

\section{Filtering Kenyan Data Through the Model}

We now use the model to interpret the joint movement of macro variables in Kenya. To do so, we filter the data through the model using the Kalman smoother described in Appendix III. The Kalman filter and smoother are recursive algorithms used to estimate a sequence of unobserved state variables whose dynamics are described by a state space model-a vector autoregression of order one (VAR(1)) — based on the observations of a sequence of other variables which are linearly related to them. In our case, the state variables are trend and gap components and the shocks - their dynamics are jointly described by the VAR(1) representation of the model solution-and the observables are the actual series.

The use of the Kalman smoother to estimate trends and gaps implies that the estimates at any point in time draw on information from the entire sample, e.g., the estimate of the output gap

\footnotetext{
${ }^{17}$ One such shock is the one that appears in the food Phillips curve. This shock can capture variations in food inflation due to temporary real factors, such as large variations in the weather that affect the production of food, or changes in food tariffs, subsidies or taxes. Understanding how these factors affect food inflation-and by how much-is an important area of research and merits further work.
} 
in 2005:Q1 depends on movements in inflation (and other observed variables) from both before and after 2005:Q1. This feature is convenient when trying to understand historical episodes, though it also implies that the economist doing the exercise can have a clearer picture of past macro developments than policy makers at the time.

We will focus primarily on two main outputs: a decomposition of most series into a trend (or potential) and a gap component, and a decomposition of the current value of any variable into the different shocks responsible for its dynamics.

\section{Decomposition into trends and gaps}

We begin the analysis by looking at the model's four main relative prices $\left(z_{t}, r l p_{t}, r l p_{t}^{*}\right.$, $\left.d e v_{t}\right)$, which are displayed in Figure 8. Kenya's real exchange rate $\left(z_{t}\right)$ has appreciated over time (see upper left quadrant), which in the model is accounted for by a smooth trend appreciation. The real exchange rate also displays some noticeable spikes, especially in 2008, accounted for by movements in the gap (the difference between the two series). The international relative price of food $\left(r l p_{t}^{*}\right.$, bottom left quadrant) also displays a relatively smooth positive trend, with large movements in the gap. Of particular interest are the large increase in international food prices in 2007-2008 and the more recent spike, which in our model are mainly accounted for by shocks to the international food price gap, although the trend also increased.

A different story emerges for the domestic relative price of food ( $r l p_{t}$, upper right quadrant). The trend component also increases over time, though it slows down at the onset of the 2007-2008 period before accelerating after that. The actual domestic relative price of food falls in early 2007, so that most of the increase in food inflation observed in 2008 can be interpreted as catching up relative to the trend. $r l p_{t}$ falls below trend again in 2010, though the gap is smaller. The deviation between domestic and foreign food prices (dev $v_{t}$, bottom right quadrant) oscillates widely, with the 2007-2008 crisis - and the more recent spike-opening up large negative gaps. Given the role of $d e v_{t}$ in the food Phillips curve, we can foresee these gaps will be inflationary.

Figure 9 plots the time series for GDP. Output experienced fast growth during 2003-2007, with a six percent average growth and 7 percent peak in 2007, before dropping to 2 percent in 2008-2009. Given our assumption about the volatility of shocks to potential, potential output displays a smooth path, although it accounts for most of the growth observed in 2003-2006. Most of the acceleration and deceleration of output around 2007 is explained by movements in the output gap, which peaks during that time but then contracts until it closes in mid 2009, in the midst of the global financial crisis. The gap opens up again from 2010 onwards.

Finally, the real interest rate (see Figure 10) displays large movements: largely positive from 2001 to early 2003, then largely negative until mid 2005 and again from mid 2007 until the end of the sample. Most of these movements are accounted for by movements in the real interest rate gap.

In sum, the trend/gap decomposition has identified various periods with sizeable gaps in output, relative prices and real interest rates. As these gaps have inflationary effects, in the 
next subsection we account for some of them and for the resulting changes in inflation in terms of the model's shocks.

\section{Decomposition into shocks}

With the help of the Kalman smoother, we decompose the dynamics of each series-both observed and unobserved-into the different estimated shocks and initial conditions (see Appendix III). Since we have 18 different shocks, we regroup them into seven groups:

- Shocks that hit the output gap: $\varepsilon_{t}^{y g a p}, \varepsilon_{t}^{\overline{r r}}$.

- Shocks that hit sectoral inflation rates: $\varepsilon_{t}^{\pi^{f}}, \varepsilon_{t}^{\pi^{n f}}, \varepsilon_{t}^{\overline{r l p}}$.

- Shocks that affect the international relative price of food: $\varepsilon_{t}^{\overline{r l p}^{*}}, \varepsilon_{t}^{r l p g a p^{*}}$.

- Shocks related to monetary policy: $\varepsilon_{t}^{R S}, \varepsilon_{t}^{\pi}$.

- Shocks that directly affect the exchange rate: $\varepsilon_{t}^{S}, \varepsilon_{t}^{\text {prem }}, \varepsilon_{t}^{\bar{z}}$.

- Shocks that originate in the rest of the world: $\varepsilon_{t}^{y g a p *}, \varepsilon_{t}^{\pi *}, \varepsilon_{t}^{R S *}, \varepsilon_{t}^{\overline{r r *}}$

- Other (initial conditions). ${ }^{18}$

The regrouping should not be interpreted too strictly, as some of the groups can overlap: some shocks to the exchange rate reflect changes in international market conditions and may be related to developments in the world economy. More generally, the model remains highly stylized and is likely to miss other transmission mechanisms which may be important in certain historical episodes. Estimated shocks may therefore correlate as a result.

It is important to reiterate that shocks affect the model variables in a number of ways. In some cases, the effect is straightforward to understand. For example, shocks to the output gap will have a direct positive effect on that variable. In other cases, the interpretation is not simple. For example, shocks that persistently raise inflation would in principle have a positive impact on the output gap since, by raising expected inflation, they lower the real interest rate. However, this effect is more than offset by the fact that monetary policy endogenously responds to increases in inflation, which then tightens real monetary conditions and results in a real appreciation, both of which reduce the output gap. It is important for the model's user to understand the different channels through which shocks affects variables.

Finally, an important caveat to the shock-based analysis is the importance of own shocks, i.e., shocks that directly affect an observed variable (like temporary shocks to food and non-food inflation $\varepsilon_{t}^{\pi^{f}}$ and $\varepsilon_{t}^{\pi^{n f}}$ ). In general, these will soak up two types of movements in that variable. The first type of movement has an economic interpretation, e.g., negative shocks to the food harvest will result in an increase in food inflation, and will show up in $\varepsilon_{t}^{\pi^{f}}$.

\footnotetext{
${ }^{18}$ As previously discussed, shocks to potential output do not affect inflation and are therefore ignored in this analysis.
} 
The second type of movement captures any high frequency dynamics in that variable without a clear economic interpretation, and which is most likely due to the fact that the model is highly stylized. The latter type may result in a overstatement of the relative important of own shocks. We will therefore complement this analysis with alternative representations of the filtration exercise.

Figure 11 shows the shock decomposition for the output gap. Three main features emerge. First, an important share of output gap fluctuations are explained by developments in the international economy: the positive gap of the mid 2000s is driven in part by strong international output, with the deceleration of the economy in mid 2008 mainly due to the effects of the global financial crisis, and the recovery since mid 2010 supported by the relative improvement in the US economy. Second, output gap shocks account for much of the economic boom in 2007, associated in part with the increase in the fiscal deficit during that period. ${ }^{19}$ Third, the Kenyan economy was supported by an accommodating monetary policy $\left(\varepsilon_{t}^{R S}<0, \varepsilon_{t}^{\pi}>0\right)$ from mid 2008 onwards, which helped offset some of the fallout from the global financial crisis. This monetary support became expansionary once the international economy recovered.

A related pattern emerges for non-food inflation (see Figure 12) ${ }^{20}$ Shocks to non-food prices account for some of its movements. The benign international environment also helps account for some of the non-food movements, especially during the global financial crisis. But more importantly, non-food prices have been consistently buoyed by accommodating monetary policy, which resulted in the large acceleration in inflation observed in 2011.

The dynamics of food inflation (Figure 13) are somewhat different. Domestic food price shocks play an important role, reflecting the importance of shocks to the domestic food harvest such as the drought of 2008-2009. More importantly, international food price shocks explain an important fraction of the upswing/downswing/upswing of food prices, while monetary conditions have again played a role. These two dynamics are then aggregated into headline inflation (Figure 14), with international conditions-including international food prices-but more importantly accommodating monetary policy being the two key factors.

We conclude this subsection with an analysis of nominal depreciation $(\Delta s)$ relative to its long-run value-given by $\overline{\Delta s}$ - presented in Figure 15. The large depreciation observed in 2009 is accounted for by the shocks to monetary policy mentioned earlier, as well as shocks to the risk premium possibly associated with the worsening of the external environment during that time. The external improvement contributes to the nominal appreciation observed in early 2010. However, since then monetary policy and exchange rate shocks-the latter possibly associated with additional balance of payment pressures from the higher food and fuel import bill—resulted in the depreciation of the currency.

\section{Alternative representations of the filtration exercise}

\footnotetext{
${ }^{19}$ Development expenditure increased by 60 percent.

${ }^{20}$ Inflation variables are demeaned.
} 
To complement the analysis, we present alternative representations of the results. First, we present the time path of selected variables. If the variable is not observed, we display the path implied by the model. If the variable is observed, we compare the observed variable with the path predicted by the model in the absence of the variable's own shock. We refer to the latter path as "KF Predicted". Second, we present an alternative decomposition, based on the terms that enter that variable's equation.

Figure 16 presents these figures for real marginal costs in the food sector $r m c_{t}^{f}$. We observe a large increase in costs in that sector, both during 2008 and in late 2010-early 2011, with an important decline in between the two spikes. A large share of the fluctuations in $r m c_{t}^{f}$ stem

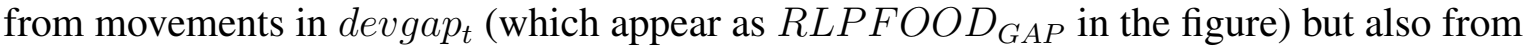
movements in the gap component of the food-based real exchange rate (the combination of the real exchange rate gap and the gap component of the domestic relative price of food, see Page 10). Movements in the output gap play a small role.

Figure 17 presents nominal interest rates. Since mid 2007, actual interest rates are consistently below those predicted by the model, with the difference due to the negative shocks to monetary policy described above. The gap is most prominent in 2008-2009, where the model called for a policy tightening which did not take place. The gap opens up again starting in mid 2010 for similar reasons, though the widening is smaller.

Regarding the factors that describe the model's implied path for interest rates, we observe that most of the persistence in interest rates is simply due to the smoothing factor in the policy rule. The increase in interest rates predicted by the model in 2008-2009 and in 2011 is due to the increase in inflation observed during those periods, as well as the nominal depreciation in the first episode, whereas the decrease in rates in between is due to the decline in inflation.

\section{A Model-Based Interpretation of Recent History}

Having provided the main results of the filtration exercise, we now provide an interpretation of recent history. This is the type of analysis that staff from the modeling division at the central bank - in charge of developing and maintaining the model and regularly updating the projection-would provide to the monetary policy committee. While based on the model, the analysis should stand on a plausible and coherent account of recent events. It would be complemented by other variables not directly used in the model (trade and balance of payments data, fiscal developments) which we do not include in this discussion for the sake of brevity.

\section{The 2007-2009 Period}

In 2007, the Kenyan economy was in full expansion. Output growth had reached its peak, driven by a very favorable external environment and positive domestic demand factors. Inflation was initially stable, with food prices actually falling thanks to a bumper harvest. 
The benign inflation outlook was also due to a neutral monetary policy and an appreciated real exchange rate.

Prospects worsened considerably starting in 2008. Growth dropped dramatically, to about 2 percent in 2008-2009. The slowdown was more severe comparing to other EAC countries as the external demand shock stemming from the global financial crisis was combined with domestic shocks - poor harvests and post-election violence. The country's external position deteriorated further as the low external demand widened current accounts deficits (not shown) and financial and capital inflows were halted due to liquidity strains on the world financial market. The nominal exchange rate sharply depreciated-by more than 20 percent in the second half of 2008, allowing the real exchange rate to return to equilibrium.

In 2008 inflation overshot its target: it increased to about 17 percent at its peak in mid 2008, from less than 2 percent a year earlier. Inflation was fueled by soaring high world food and oil prices as well as the domestic shocks mentioned above. To assess how important the increase in international food prices was for domestic inflation, Figure 18 shows the impact of the shocks to international prices identified by the model during 2007 and 2008, depending on whether the central bank responds or does not respond. The effects are sizeable and help explain the increase in domestic inflation, even if monetary policy would have responded-which it did not (see below).

As the global crisis unfolded and international commodity prices plummeted in the second half of 2008 and all through 2009, and the domestic economy slowed down, inflationary pressures subsided. This was the case even though the nominal depreciation during this period was the highest since 1998. Note that the CBK did not tighten policy. Instead, nominal short term interest rates declined. It can be argued that both fiscal (not shown) and monetary policy turned to a countercyclical position to support the domestic economy once it started to decelerate.

\section{The 2010-2011 Period}

Real growth rebounded, reaching approximately 5 percent in 2010 and reopening the output gap. The recovery was driven by an improvement in external demand as well as the accommodating monetary policy. Kenya also began to experience depreciation pressures which reached a peak in mid 2011. These stem from a combination of balance of payment pressures and low interest rates.

Driven by the events from 2009, inflation fell to less than 4 percent in mid 2010 before climbing again. Non-food price inflation soared due to the nominal exchange rate depreciation. The positive output gap also contributed to the non-food inflation acceleration, but its impact was moderate compared to import prices-real depreciation. The model estimation suggests that the demand pressures during 2011 were close to the highest within the historical sample. Food price inflation was also lifted by the depreciation of the exchange rate and increasing import prices. In addition, world food prices grew fast in the second half of 2010 and at the beginning of 2011. 


\section{APPLYING THE MODEL FOR MACRO FORECASTING IN KENYA}

This section assesses the forecasting power of the model. We study two types of forecast: historical in-sample simulations and out-of-sample forecast.

\section{A. In-sample forecasting properties}

In-sample forecasts are mechanical model forecasts created every quarter. Each model projection is run with zero future shocks starting at the smoothed means and uses only the data set up to the starting period. Furthermore, forecasts are conditioned on the development of external variables along with the real exchange rate trend and the implicit inflation target. ${ }^{21}$ We exploit the implicit inflation target to better capture the monetary policy setting and implementation.

The variables used for conditioning are as follows:

- the US output gap,

- the Fed funds rate and the trend of the real Fed funds rate,

- US CPI inflation,

- the world price of food and its trend,

- the real exchange rate trend, and

- the implicit inflation target.

Outcomes of the in-sample forecasts are compared with the actual values or with the smoothed trajectories, as is the case of the output gap. We report the historical forecasting performance for the main four variables: year-on-year CPI inflation, the nominal KES per USD exchange rate, the short-term interest rate, and the output gap. The forecasts are presented in Figure 19. ${ }^{22}$ The sample period covers 2003Q1-2011Q2.

We organize the discussion of in-sample forecasting performance around three periods:

- Pre-2008 period. The historical model forecast capture the general tendencies in this period relatively well. It predicts the increase in nominal interest rates between 2003 and 2005, as well as the relative interest rate stability from mid 2005 onwards. The model succeeds in forecasting the path of the nominal exchange rate, though this is due

\footnotetext{
${ }^{21}$ This conditioning still misses expert judgments as a common input to model based forecasts at central banks.

${ }^{22}$ The figures plot the historical forecasts as dotted lines. The forecasts start in the first and third quarter of a year for presentation purposes. The tick blue line depicts the actual data.
} 
to the conditioning of the forecast on the path of the equilibrium real exchange rate. The model also correctly predicts the sustained expansion in the output gap-based on the path of the US output gap and negative real interest rates-and some of the increase and subsequent decrease in inflation during 2004-2006.

- The 2008-2010 period. The historical simulations capture the general directions, but not the magnitudes of the macroeconomic fluctuations owing to a number of exogenous shocks (the global crisis, adverse weather conditions, and post-election violence). These factors result in an undershooting of the inflation surge predicted for 2008. Moreover, the model simulations suppose that the central bank tightened its policy in order to keep inflation close to the target. The policy tightening-in the model forecasts-opens a negative output gap which is not observed in the data. The simulations capture the increase of the country risk premium and the sharp nominal exchange rate depreciation in the second half of 2008, but only partially and thanks to knowledge of the equilibrium real exchange rate.

- The end 2010-2011 period. As inflation started to soar by the end of 2010, the model predicts a tightening of monetary policy. The repo rate forecasts are therefore above the actual data. The observed low interest rates are interpreted by the model as policy misalignments, and the magnitude of policy tightening is gradually rising through this period. $^{23}$ The policy tightening predicted by the model forecasts keeps inflation below the actual data, which is also lower given the smaller depreciation of the nominal exchange rate (and the resulting inflation of import prices). Similarly, tight monetary conditions imply a lower output gap than what is inferred from the entire sample.

We also compare the root mean square errors (RMSE) of the in-sample simulations with projections based on the random walk model (see Table 4). The RMSEs are reported for different horizons and the comparison uses all historical forecasts, i.e. forecasts created at each historical data point. Numbers below 1 indicate that the RMSE of in-sample structural model forecasts is lower than the RMSE of the random walk and vice versa. Results suggest that the model forecasts perform better than the random walk ones. This is particularly the case of inflation, nominal exchange rate, and the repo rate. The model forecasts are better at all horizons. In sum, the in-sample forecasting properties of the model are satisfactory. They are limited however, in the presence of large exogenous shocks or sustained policy misalignments.

\section{B. Out-of-sample forecasting}

We now assess the model's performance in a real time historical exercise, namely the period of increasing inflation in mid 2011. The exercise was performed in September 2011, using the data up to 2011:Q2. Unlike the in-sample performance presented above, the external assumptions used are also from September 2011. The model forecast is then compared with

\footnotetext{
${ }^{23}$ Notice the rising slope of interest rate projections.
} 
actual developments - based on data that has become available since then. The forecast and the data are presented in Figure 20.

We believe that a real-time, careful exercise of model-based projection is a superior measure of model qualities, compared to more mechanistic measures such as the one-step ahead RMSEs presented earlier. Our goal is to analyze medium-term developments and tendencies useful for policy prescription, rather than capture high-frequency movements.

As discussed earlier, Kenya experienced soaring inflation in the second half of 2011, driven mainly by food prices. According to the model analysis, food prices inflation was driven in part by the surge in the world food prices in the second half of 2010 and at the beginning of 2011. Importantly, the world food price increase was aggravated by depreciation of the nominal exchange rate. Non-food price inflation also rose reflecting the nominal depreciation. On the top of that, a positive output gap contributed to the non-food inflation surge, but its impact is moderate compared to that of depreciation. The estimated output gap is also in line with the fast credit growth observed during 2010-2011. Importantly, the analysis shows that both in 2008 and 2011 part of the exchange rate depreciation was a consequence of looser monetary policy. This is also corroborated by narrative evidence from financial markets, where worries of excessive inflation were present.

\section{The model forecast}

As discussed in the previous section, the model forecast suggested that a policy tightening was needed to curb inflationary pressures. However, the reaction of monetary policy was delayed through the first half of 2011. The CBK provided liquidity to the banks through reverse repos until 2011Q1. Since then the CBK started to withdraw liquidity, but the repo rate was kept close to $5.75 \%$ until mid June 2011. Given soaring inflation, monetary policy became excessively loose sparking depreciation expectations. Commercial banks exploited the arbitrage opportunities from the expected depreciation by borrowing from the central bank overnight discount window at low rates and building up foreign exchange positions. A depreciation spiral emerged.

The central bank recognized symptoms of the exchange rate crisis in 2011Q3 and tightened monetary policy. However, the CBK implemented a series of non-standard and discretionary measures which further increased the uncertainty. As a result, nominal exchange rate depreciation continued in 2011Q3. A firm monetary tightening finally took place in 2011 Q4.

The model correctly predicted the tightening, though it under-predicted its magnitude. The large increase in rates most likely reflects an objective to restore credibility, an aspect of policy our model does not address. As the magnitude of the tightening was larger, the nominal exchange rate appreciation has also been stronger than what was forecasted. Overall inflation decelerated, although food inflation has remained high. 


\section{Discussion}

The use of the model for policy analysis has yielded various insights into the drivers of inflation in Kenya. One such insight is the role of excessively accommodating monetary policy in recent years. In this section we discuss some likely factors behind the policy stance during this period.

Monetary Policy operates in an environment of considerable uncertainty and incomplete information. The central bank must rely on current and leading indicators that are noisy and may not reveal a clear picture until incipient inflationary pressures have built up, in which case it is too late to offset the impact on actual inflation given the lags in the transmission of monetary policy. Because of these information lags, central banks often find themselves responding to the inflationary effects of past shocks rather than responding to new developments. In the case of sub-Saharan Africa, these challenges are compounded by the scarcity of high frequency indicators.

An additional challenge for monetary policy is the management of multiple objectives, either explicit and implicit. While most if not all central banks place price stability as their primary objective, they also attempt to support economic growth and-at times-financial sector development and credit growth. While these objectives are sometimes consistent, they can also conflict with one another. In addition, because excessively tight or accommodating policies do not immediately show up in high inflation, it may take time before the central bank can realize the inconsistency. A related challenge is that the legacy of monetary aggregate targeting can at times lead to inconsistent views about the stance of policy if broad money growth appears consistent with previously set targets; even though interest rates may be too high or low.

In the case of Kenya, the central bank loosened its policy in response to the global financial crisis of 2008-2009, which had resulted in lower economic growth, contribute to a large decrease in inflation and had negative implications for the growth of domestic credit. The policy loosening was maintained beyond this period, however, with rates continuously declining and reaching 1 percent by the end of 2011.

While very low interest rates should have acted as a sinal that monetary policy was excessively accommodative, the central bank justified its stance in its December 2011 Monetary Policy Statement by emphasizing objectives for monetary and credit aggregates: "The programmed growth in money supply ... was considered adequate to support economic growth through expansion of credit to private sector... Generally, broad money supply, M3, remained within the set target . Credit to private sector increased, which was virtually on target." (Monetary Policy Statement, Dec 2010, pp. 3). It is worth noting that reserve money growth was also indicative of expansionary policies, as this variable was overshooting its target consistently through $2011 .^{24}$ Despite the overshooting of reserve money, as broad money and credit aggregates were in line with their targets, the perception was that monetary

\footnotetext{
${ }^{24}$ See Monetary Policy Statement by Central Bank of Kenya, December 2011.
} 
policy would have no effect on demand-driven inflation (MPS, pp. 3). This state of affairs may have been compounded by the sustained decline inflation between late 2008 and mid 2010.

In hindsight, the targets for broad money and credit were based on an optimistically low assumption for broad money velocity and optimistic assumptions about the credit growth rates consistent with stable inflation. More generally, had the policy regime placed more emphasis on interest rates as indicating the stance of policy and less emphasis on credit growth and other quantitative targets, a clearer picture about the stance of policy may have emerged. It is worth stressing that an analysis of monetary policy in Kenya can be done independently of any assumptions about credit and money growth, as the current paper indicates.

\section{Conclusion}

In this paper we have provided a blueprint of a forecasting and policy analysis system (FPAS) for low-income countries, with an application to Kenya. In particular, we have extended the standard framework to include an explicit role for food prices, by introducing two separate Phillips curves (one for food and one for non-food), and by paying special attention to the domestic and foreign relative food prices (both trend and gap component).

We have used the model to run various exercises. First, we filter key macroeconomic series from Kenya through the model, in order to recover a model-based decomposition of most series into trend and gap components, and to discuss the quantitative significance of various factors (international shocks, monetary policy). Second, we assess the performance of the model by analyzing impulse response functions and in-sample historical forecasts. Finally, we perform an out-of-sample forecast to identify where the economy-and therefore policy-was likely headed given the inflationary pressures at the time.

We find that, while imported food price shocks have accounted for some of the inflation dynamics in Kenya, both in 2008 but also recently, an accommodative monetary policy also played an important role. Our out-of-sample exercise indicated that policy needed to be tightened, which is exactly what the central bank did by the end of 2011 . We believe the out-of-sample performance of the model, together with its in-sample properties and more generally its ability to provide a plausible interpretation of recent events in Kenya, validates the use of these types of models for policy analysis in low-income countries.

We acknowledge that, while the exercise has proven useful, much uncertainty surrounds the analysis of monetary policy in Kenya and LICs in general. We have much to learn about important features of these economies, including: the (micro) structure of the food sector and its exposure to domestic and international shocks, the importance of other supply shocks, the degree of price and wage stickiness, the implications of limited financial participation and 
imperfect capital mobility for the transmission mechanism, and the role of alternative instruments such as sterilized foreign exchange interventions ${ }^{25}$.

One next step is to apply a model such as the one presented here to help support monetary policy in Kenya, and indeed in other low-income countries that are attempting to conduct forward-looking monetary policy in the context of a flexible exchange rate regime. We believe the results of this paper, and experience in a number of emerging markets, suggests that this will prove useful. ${ }^{26}$ A number of practical issues will need to be confronted, such as the definition of the policy instrument, the functioning of the interbank market, the role of money and exchange rate management in policy making, and scarce high-frequency data. Experience suggests, however, that efforts to think and act more systematically about monetary policy can complement and even promote the development of better functioning financial markets and, over time, improve the functioning and understanding of the transmission mechanism.

\footnotetext{
${ }^{25}$ Work along these lines is underway. See for example Adam and others (2012) and Portillo and Zanna (2013) on food prices, Mishra and others (2011) and Baldini and others (2012) on the role of the financial sector, and Ostry and others (2012) and Benes an other (2012) on foreign exchange intervention
}

${ }^{26}$ See Laxton and others (2009). 


\section{REFERENCES}

Adam, Christopher, David Kwimbere, Wilfred Mbowe, and Stephen OConnell 2012, "Food Prices and Inflation in Tanzania, Manuscript, Bank of Tanzania and International Growth Centre.

Baldini, Alfredo, Jaromir Benes, Andrew Berg, Mai C. Dao, and Rafael Portillo, 2012, "Monetary Policy in LowIncome Countries in the Face of the Global Financial Crisis: The Case of Zambia, IMF Working Paper 12/94.

Benes, Jaromir, Andrew Berg, Rafael Portillo, and David Vavra, 2011, ”Modeling Sterilized Interventions and Balance Sheet Effects of Monetary Policy, IMF Working Paper.

Berg, Andrew, Philip D. Karam, and Douglas Laxton, 2006, ”A Practical Model-Based Approach to Monetary Policy Analysis-Overview,IMF Working Paper 06/80.

Berg, Andrew, Rafael Portillo, and Filiz Unsal, 2010, ”Optimal Adherence to Money Targets in LowIncome Countries, IMF Working Paper 10/134.

Blanchard, Olivier, and Charles Kahn, 1982, "The Solution of Linear Difference Models under Rational Expectations, Econometrica, Vol. 48(5), 13051313.

Calvo, Guillermo A., 1983, "Staggered prices in a utility-maximizing framework, Journal of Monetary Economics, Vol. 12(3), 383398.

Central Bank of Kenya, 2010, ’Monetary Policy Statement, December. (Nairobi: Central Bank of Kenya).

Christiano, Lawrence J., Martin Eichenbaum, and Charles L. Evans. 2005, ’Nominal Rigidities and the Dynamic Effects of a Shock to Monetary Policy," Journal of Political Economy, 113(1): 145 .

Clarida, Richard, Jordi Gali J, and Mark Gertler, 1999, "The Science of Monetary Policy: A New Keynesian Perspective, Journal of Economic Literature, Vol. 37(4), 16611707.

Hamilton, James. (1995). Time Series Analysis. Princeton, NJ: Princeton University Press.

International Monetary Fund, 2008, "Monetary and Exchange Rate Policies in Sub-Saharan Africa,in Regional Economic Outlook, Sub-Saharan Africa, chapter 2. IMF. Washington, DC.

International Monetary Fund, 2011, "Target What You Can Hit: Commodity Price Swings and Monetary Policy,in World Economic Outlook, chapter 3. IMF. Washington, DC.

Ireland, Peter, 2007, "Changes in the Federal Reserves Inflation Target: Causes and Consequences, Journal of Money, Credit and Banking, Vol. 39(8), 18511882. 31

Gali, Jordi, and Tommasso Monacelli, 2005, "Monetary Policy and Exchange Rate Volatility in a Small Open Economy Model, Review of Economic Studies, Vol. 72, 707734. 
Laxton, Douglas, David Rose, and Alasdair Scott, 2009, 'Developing a Structured Forecasting and Policy Analysis System to Support Inflation-Forecast Targeting (IFT), IMF Working Paper 09/65.

Mishra, Prachi, Peter Montiel, and Antonio Spilimbergo, 2010, "Monetary Transmission in Low Income Countries, IMF Working Paper 10/223.

Ostry, Jonathan D., Atish R. Gosh, and Marcos Chamon, 2012, "Two Targets, Two Instruments: Monetary and Exchange Rate Policies in Emerging Market Economies, IMF Staff Discussion Note 12/01.

Portillo, Rafael, and Luis Felipe Zanna 2013, "On the FirstRound Effects of Food Price Shocks: the Role of the International Asset Market Structure, Manuscript, IMF.

Smets, Frank, and Raf Wouters, 2003, "Shocks and Frictions in US Business Cycles: A Bayesian DSGE Approach, Manuscript, European Central Bank. 


\section{Appendix I. Deriving Phillips Curves from Micro-Foundations}

\section{The non-food sector}

We assume the non-food sector is composed of a continuum of monopolistic competitors, each providing a variety of non-food $Y_{t}^{n f}(i)$, with $\left.i \epsilon[0,1]\right)$. Varieties are aggregated into a Dixit-Stiglitz function:

$$
Y_{t}^{n f}=\left[\int Y_{t}^{n f}(i)^{\frac{\epsilon_{t}^{n f}-1}{\epsilon_{t}^{n f}}}\right]^{\frac{\epsilon_{t}^{n f}}{\epsilon_{t}^{n f}-1}},
$$

where $\epsilon_{t}^{n f}$ is the time-varying elasticity of substitution between varieties. Cost minimization by consumers results in the following demand for variety $(i)$ :

$$
Y_{t}^{n f}(i)=\left(\frac{P_{t}^{n f}(i)}{P_{t}^{n f}}\right)^{-\epsilon_{t}^{n f}} Y_{t}^{n f}
$$

where $P_{t}^{n f}(i)$ is the price charged by firm $(i)$ and $P_{t}^{n f}$ is the price index for the non-food sector:

$$
P_{t}^{n f}=\left[\int P^{n f}(i)_{t}^{1-\epsilon_{t}^{n f}}\right]^{\frac{1}{1-\epsilon_{t}^{n f}}} .
$$

Non-food is produced using a CES combination of imports and domestic labor:

$$
Y_{t}^{n f}(i)=A_{t}^{n f}\left[\alpha^{n f \frac{1}{\mu^{n f}}} M_{t}^{n f}(i)^{\frac{\mu^{n f}-1}{\mu^{n f}}}+\left(1-\alpha^{n f}\right)^{\frac{1}{\mu^{n f}}} L_{t}^{n f}(i)^{\frac{\mu^{n f}-1}{\mu^{n f}}}\right]^{\frac{\mu^{n f}}{\mu^{n f}-1}},
$$

where $\mu^{n f}$ is the elasticity of substitution between labor and imports and $\alpha^{n f}$ is the weight of imports in production.

Firms in the non-food sector make two decisions to maximize profits. First, they choose an optimal combination of inputs to minimize costs, conditioned on the above production function. This results in the following demand functions:

$$
\begin{gathered}
M_{t}^{n f}(i)=\alpha^{n f}\left(\frac{W_{t}^{n f}}{M C_{t}^{n f}}\right)^{-\mu^{n f}} Y_{t}^{n f}(i), \\
L_{t}^{n f}(i)=\left(1-\alpha^{n f}\right)\left(\frac{S_{t} P_{t}^{*}}{M C_{t}^{n f}}\right)^{-\mu^{n f}} Y_{t}^{n f}(i),
\end{gathered}
$$

where $W_{t}^{n f}$ is the nominal wage paid in the non-food sector, $S_{t}$ is the nominal exchange rate, $P_{t}^{*}$ is the international price index, and $M C_{t}^{n f}$ is the nominal marginal cost in the non-food sector:

$$
M C_{t}^{n f}=\frac{1}{A^{1-\mu^{n f}}}\left[\alpha\left(S_{t} P_{t}^{*}\right)^{1-\mu}+(1-\alpha)\left(W_{t}^{n f}\right)^{1-\mu^{n f}}\right]^{\frac{1}{1-\mu^{n f}}} .
$$


Second, firms set prices for their varieties. As in Calvo (1983), firms are not allowed to change their prices unless they receive a random signal. The probability that a given price can be re-optimized in any particular period is constant and equal to $\left(1-\theta^{n f}\right)$. We follow Christiano, Eichenbaum and Evans (2001), in assuming that firms that do not receive a price signal index their prices to last periods inflation rate (in the non-food sector).

If firm $i$ gets the random signal at time $t$, it chooses a reset price $\bar{P}^{n f}(i)_{t}$ to maximize its discounted stream of expected profits:

$\operatorname{Max} E_{t}\left[\Sigma_{j=0}^{\infty}\left(\beta \theta^{n f}\right)^{j} \lambda_{t}\left[\left(\frac{\bar{P}_{t}^{n f}(i)}{P_{t+j}^{n f}} \frac{P_{t-1+j}^{n f}}{P_{t-1+j}^{n f}}\right)^{-\epsilon_{t}^{n f}} Y_{t+j}^{n f}\left(\bar{P}_{t}^{n f}(i) \frac{P_{t-1+j}^{n f}}{P_{t-1+j}^{n f}}-M C_{t+j}^{n f}(1-\iota)\right)\right]\right.$,

where $\beta$ is the intertemporal rate of preference, $\lambda_{t}$ is the stochastic discount factor, and $\iota$ is a production subsidy that serves to offset the distortion created by firms' market power.

Profit maximization results in the following reset price (normalized by the headline CPI, $\left.P_{t}^{c p i}\right)$ :

$$
\bar{P}_{t}^{n f}(i)=\frac{\epsilon_{t}^{n f}}{\epsilon_{t}^{n f}-1}(1-\iota) \frac{E_{t}\left[\sum_{j=0}^{\infty}\left(\beta \theta^{n f}\right)^{j} \lambda_{t}\left[\left(\frac{1}{P_{t+j}^{n f}} \frac{P_{t-1+j}^{n f}}{P_{t-1+j}^{n f}}\right)^{-\epsilon_{t}^{n f}} Y_{t+j}^{n f} M C_{t+j}^{n f}\right]\right]}{E_{t}\left[\sum_{j=0}^{\infty}\left(\beta \theta^{n f}\right)^{j} \lambda_{t}\left[\left(\frac{1}{P_{t+j}^{n f}} \frac{P_{t-1+j}^{n f}}{P_{t-1+j}^{n f}}\right)^{-\epsilon_{t}^{n f}} Y_{t+j}^{n f} \frac{P_{t-1+j}^{n f}}{P_{t-1}^{n f}}\right]\right]} .
$$

The aggregate price index in the non-food sector is the weighted sum of those prices that were reset (of which there is mass $\left(1-\theta^{n f}\right)$ ) and those prices that were not reset (of which there is mass $\theta^{\text {nf }}$ and which can be approximated with yesterday's price index) but that are indexed to past inflation:

$$
P_{t}^{n f}=\left[\theta^{n f}\left(\bar{P}^{n f}(i)_{t}\right)^{1-\epsilon_{t}^{n f}}+\left(1-\theta^{n f}\right)\left(P_{t-1}^{n f} \frac{P_{t-1}^{n f}}{P_{t-2}^{n f}}\right)^{1-\epsilon_{t}^{n f}}\right]^{\frac{1}{1-\epsilon_{t}^{n f}}} .
$$

At steady state, the elasticity of substitution between varieties is constant $\left(\epsilon_{t}^{n f}=\epsilon\right)$ and the government sets a subsidy $\iota=1 / \epsilon$. Inflation is set to zero. Under the assumption that the real exchange rate $\left(Z=\left(S_{t} P_{T}^{*}\right) / P_{t}^{c p i}\right)$ and the real wage $\left(W_{t}^{n f} / P_{t}^{c p i}\right)$ are normalized to one, it must be the case that $\bar{P}^{n f}(i) / P^{c p i}=P^{n f} / P^{c p i}=M C^{n f} / P^{c p i}=1$ at steady state. ${ }^{27}$

Log-linearizing the equations for the reset price and the aggregate price index (at both time $t$ and time $t+1$ ), and after considerable rearrangements of terms, yields the following Phillips

\footnotetext{
${ }^{27}$ In the appendix, we abstract from trends in relative prices for the sake of clarity. These can be introduced without affecting the results presented here.
} 
curve:

$$
\begin{gathered}
\pi_{t}^{n f}-\bar{\pi}_{t}^{n f}=\lambda_{1}\left(E_{t}\left[\pi_{t+1}^{n f}\right]-\bar{\pi}_{t}^{n f}\right)+\left(1-\lambda_{1}\right)\left(\pi_{t-1}^{n f}-\bar{\pi}_{t}^{n f}\right)+\lambda_{3} r m c_{t}^{n f}+\varepsilon_{t}^{n f}, \\
\lambda_{1}=\frac{\beta}{1+\beta}, \quad \lambda_{3}=\frac{\left(1-\theta^{n f}\right)\left(1-\theta^{n f} \beta\right)}{\theta^{n f}(1+\beta)}, \quad \varepsilon_{t}^{n n}=-\frac{1-\theta^{n f}}{\theta^{n f}} \frac{1}{\epsilon-1}\left(\log \left(\epsilon_{t}^{n f}\right)-\log (\epsilon)\right) .
\end{gathered}
$$

The term $r m c_{t}^{n f}$ denotes the natural logarithm of marginal costs in the non-food sector relative to the price index in that sector:

$$
r m c_{t}^{n f}=\alpha^{n f} \log \left(\frac{S_{t} P_{t}^{*}}{P_{t}^{n f}}\right)_{t}+\left(1-\alpha^{n f}\right) \log \left(\frac{W_{t}^{n f}}{P_{t}^{n f}}\right)=\alpha^{n f} z_{t}^{n f}+\left(1-\alpha^{n f}\right) w_{t}^{n f},
$$

The above Phillips curve is similar to the Phillips curve on page 12, with only one difference: the Phillips curve used in the model allows imported inflation to enter directly.

To equate the above marginal cost equation with the equation on page 12 we note that, under flexible prices, the term $r m c_{t}^{n f}$ equals zero, as non-food prices would equal nominal marginal costs in that sector. Defining the flexible-price equilibrium with an overbar, the following relation holds:

$$
\overline{r m c}_{t}^{n f}=\alpha^{n f} \bar{z}_{t}^{n f}+\left(1-\alpha^{n f}\right) \bar{w}_{t}^{n f}=0
$$

Taking differences between $r m c_{t}^{n f}$ and $\overline{r m c_{t}^{n f}}$ yields:

$$
r m c_{t}^{n f}=\alpha^{n f} z^{n f} \operatorname{gap}_{t}+\left(1-\alpha^{n f}\right) w^{n f} \operatorname{gap}_{t},
$$

where $z^{n f} g a p_{t}=z_{t}^{n f}-\bar{z}_{t}^{n f}$ and $w^{n f} g a p_{t}=w_{t}^{n f}-\bar{w}_{t}^{n f}$. Finally, we make the standard assumption that the non-food sector real wage gap is proportional to the output gap. This leads lead to the equation for real marginal costs in the non-food sector in page 12:

$$
r m c_{t}^{n f}=\lambda_{4} y_{g a p}+\left(1-\lambda_{4}\right) z^{n f} g p_{t},
$$

where $\lambda_{4}=\left(1-\alpha^{n f}\right)$.

\section{The food sector}

The structure of the food sector is similar to that in the non-food sector, with $\left(\epsilon_{t}^{f}, \theta^{f}\right)$ replacing $\left(\epsilon_{t}^{n f}, \theta^{n f}\right)$. This results in the following Phillips curve for food:

$$
\begin{gathered}
\pi_{t}^{f}-\bar{\pi}_{t}^{f}=b_{1}\left(E_{t}\left[\pi_{t+1}^{f}\right]-\bar{\pi}_{t}^{f}\right)+\left(1-b_{1}\right)\left(\pi_{t-1}^{f}-\bar{\pi}_{t}^{f}\right)+b_{3} r m c_{t}^{f}+\varepsilon_{t}^{\pi^{f}}, \\
b_{1}=\frac{\beta}{1+\beta}, \quad b_{3}=\frac{\left(1-\theta^{f}\right)\left(1-\theta^{f} \beta\right)}{\theta^{f}(1+\beta)}, \quad \varepsilon_{t}^{\pi^{f}}=-\frac{1-\theta^{f}}{\theta^{f}} \frac{1}{\epsilon-1}\left(\log \left(\epsilon_{t}^{f}\right)-\log (\epsilon)\right),
\end{gathered}
$$

and where $r m c_{t}^{f}$ denotes the natural logarithm of marginal costs in the food sector relative to the food price index. This Phillips curve is similar to the food Phillips curve on page 12, with 
the same exception as before. Although in principle $b_{1}$ should equal $\lambda_{1}$, we allow for the two parameters to differ.

To define $r m c_{t}^{f}$, we assume a different production function. Representative firm $i$ in the food sector require labor $L^{f}(i)_{t}$, imported non-food $M^{f}(i)_{t}$ and imported food $M^{f f}(i)_{t}$ to produce domestic food. The production function is the following:

$$
Y^{f}(i)_{t}=A_{t}^{f}\left[\alpha_{1}^{f \frac{1}{\mu^{f}}} M^{f}(i)_{t}^{\frac{\mu^{f}-1}{\mu f}}+\alpha_{2}^{f \frac{1}{\mu^{f}}} L^{f}(i)_{t}^{\frac{\mu^{f}-1}{\mu^{f}}}+\left(1-\alpha_{1}^{f}-\alpha_{2}^{f}\right)^{\frac{1}{\mu^{f}}} M^{f f}(i)_{t}^{\frac{\mu^{f}-1}{\mu^{f}}}\right]^{\frac{\mu^{n f}}{\mu^{n f}-1}},
$$

This production structure results in the following definition for $r m c_{t}^{f}$ :

$r m c_{t}^{f}=\alpha_{1}^{f} \log \left(\frac{S_{t} P_{t}^{*}}{P_{t}^{f}}\right)+\alpha_{2}^{f} \log \left(\frac{W_{t}^{f}}{P_{t}^{f}}\right)+\left(1-\alpha_{1}^{f}-\alpha_{2}^{f}\right) \log \left(\frac{S_{t} P_{t}^{* f}}{P_{t}^{f}}\right)=\alpha_{1}^{f} z_{t}^{f}+\alpha_{2}^{f} w_{t}^{f}-\left(1-\alpha_{1}^{f}-\alpha_{2}^{f}\right) d e v_{t}$,

where $\operatorname{dev}_{t}=\log \left(P_{t}^{f}\right)-\log \left(P_{t}^{* f}\right)-\log \left(S_{t}^{f}\right)$. As in the non-food sector, $r m c_{t}^{f}$ can be redefined as:

$$
r m c_{t}^{f}=\alpha_{1}^{f} z^{f} g a p_{t}+\alpha_{2}^{f} w^{f} \text { gap }_{t}-\left(1-\alpha_{1}^{f}-\alpha_{2}^{f}\right) \text { devgap }_{t} .
$$

Finally, we make a similar assumption as in the non-food sector: the real wage in the food sector is proportional to the output gap. This leads to an equation for real marginal costs in the non-food sector that is similar to that on page 12:

$$
r m c_{t}^{f}=b_{4} \text { ygap }_{t}+\left(1-b_{4}-b_{5}\right) z^{f} \text { gap }_{t}-b_{5} \text { devgap }_{t},
$$

where $b_{4}=\alpha_{2}^{f}, b_{5}=\left(1-\alpha_{1}^{f}-\alpha_{2}^{f}\right)$. 
APpendix II. Data Series

Data

\begin{tabular}{cccc}
\hline Variable & Data Used & Source & Remarks \\
\hline$s$ & Market rate, Shilling/Dollar & IMF IFS & Repo rate (2000:1 2009:1,2011:5 2011:6), \\
$r s$ & Repo, reverse Repo rates & CBK & Reverse repo (2009:3 2011:4), \\
& & & Avg repo and reverse repo 2009M2. \\
& & Interpolated, \\
$y$ & Non-Agricultural GDP & KNBS & smoothed with an HP filter $(\lambda=0.8)$. \\
$p^{c p i}$ & CPI & KNBS, IMF staff & \\
$p^{f}$ & Food Price Index & KNBS, IMF staff & \\
$p^{n f}$ & Non-food Price Index & KNBS & \\
$p^{* c p i}$ & US CPI & IMF IFS & \\
$r s^{*}$ & Fed Funds rate & IMF IFS & \\
$\overline{r r}^{*}$ & US equilibrium real interest rates & IMF modeling group & \\
$y g a p^{*}$ & US Output Gap & IMF IFS & US GDP, HP filtered. \\
$p^{* f}$ & International Food Commodity Index & FAO & \\
\hline
\end{tabular}




\section{APpendix III. Solving ANd Using The Model}

\section{Solving and Simulating the Model}

The actual model is a linear semi-structural forward looking model, with model-consistent expectations, of the form $F\left(X_{t-1}, X_{t}, X_{t+1}, \varepsilon_{t} \mid \theta\right)=0$, where $X_{t}$ denotes the vector of endogenous variables, $\varepsilon_{t}$ are exogenous variables (shock innovations) and $\theta$ denotes the parameters of the model. The model is solved using a variant of the Blanchard and Kahn algorithm (see Blanchard and Kahn (1982)), implemented using the IRIS Toolbox for Matlab. ${ }^{28}$

\section{Kalman filter \& Smoother}

To estimate the model's structural shocks and unobserved variables, we proceed as follows. First, we present the solution of the model in state space representation:

$$
X_{t}=T X_{t-1}+R \varepsilon_{t} \quad \varepsilon_{t} \sim N\left(0, \Sigma_{\varepsilon}\right)
$$

where $\Sigma_{\varepsilon}$ is the variance covariance matrix of the shock innovations. Model variables $X_{t}$ are linearly related to observed variables $Y_{t}$ (inflation, output, exchange rates, etc) via a measurement equation:

$$
Y_{t}=Z X_{t}+H \eta_{t} \quad \eta_{t} \sim N\left(0, \Sigma_{\eta}\right)
$$

where $\eta_{t}$ indicates potential noise in the relation (and $\Sigma_{\eta}$ denotes the noise covariance).

We then apply the Kalman filter to the data, using the system A1-A2. The Kalman filter is a recursive algorithm used for updating estimates of the sequence of $X_{t}$ and $\varepsilon_{t}$ based on observations of $Y_{t}$. It can be summarized by the following sequence (see Ch. 13 in Hamilton (1995)):

$$
\begin{gathered}
\hat{X}_{t+1 \mid t}=T \hat{X}_{t \mid t}=\hat{X}_{t \mid t-1}+P_{t \mid t-1} Z\left(Z^{\prime} P_{t \mid t-1} Z+\Sigma_{\eta}\right)^{-1}\left(Y_{t}-Z X_{t \mid t-1}\right), \\
P_{t+1 \mid t}=\left(T-K_{t} Z^{\prime}\right) P_{t \mid t-1}\left(T-K_{t} Z^{\prime}\right)+K_{t} \Sigma_{\eta} K_{t}^{\prime}+\Sigma_{\varepsilon} \\
K_{t}=T P_{t \mid t-1} Z\left(Z^{\prime} P_{t \mid t-1} Z+\Sigma_{\eta}\right)^{-1}, \quad \text { for } \quad t=1, \ldots, T .
\end{gathered}
$$

$P_{t+1 \mid t}$ is mean square error of the estimate $\hat{X}_{t+1 \mid t}$. The recursion is initiated with $\hat{X}_{1 \mid 0}=E\left(X_{1}\right)$ and $\operatorname{vec}\left(P_{1 \mid 0}\right)=\left[I_{r^{2}}-(T \otimes T)\right]^{-1} \operatorname{vec}(Q)$.

The Kalman filter provides the best estimate of $X_{t}$ using information up until time $t$. For many purposes, including for the filtration exercise presented in the text, it is useful to

\footnotetext{
${ }^{28}$ See e.g. www.iris-toolbox.com or www. dynare.org
} 
construct an estimate of $X_{t}$ using the entire sample. This can be done using the Kalman smoother, another recursive algorithm which starts backwards from the last observation:

$$
\begin{gathered}
\hat{X}_{t \mid T}=\hat{X}_{t \mid t}+J_{t}\left[\hat{X}_{t+1 \mid T}-\hat{X}_{t+1 \mid t}\right], \\
J_{t}=P_{t \mid t} T^{\prime} P_{t+1 \mid t}, \\
P_{t \mid T}=P_{t \mid t}+J_{t}\left(P_{t+1 \mid T}-P_{t+1 \mid t}\right) J_{t}^{\prime}, \quad \text { for } t=T, T-1, \ldots, 1,
\end{gathered}
$$

where:

$$
P_{t \mid t}=P_{t \mid t-1}-P_{t \mid t-1} Z\left(Z^{\prime} P_{t \mid t-1} Z+\Sigma_{\eta}\right) Z^{\prime} P_{t \mid t-1},
$$

and $P_{t \mid T}$ is the mean square error of the smoothed estimate $\hat{X}_{t+1 \mid T}$.

For the sake of intuition, it is important to understand that the Kalman smoother is essentially a recursive implementation of a least squares problem of minimizing

$J=(1 / 2) \sum_{t=1}^{T} \varepsilon_{t}^{\prime}\left(R \Sigma_{\varepsilon} R^{\prime}\right) \varepsilon_{t}+(1 / 2) \sum_{t=1}^{T} \eta_{t}^{\prime}\left(H \Sigma_{\eta} H^{\prime}\right) \eta_{t}+\left(X_{0}-E\left[X_{0}\right]\right) P_{0}\left(X_{0}-E\left[X_{0}\right]\right)$

In general, including in the main body of the paper, there are more structural shocks-number of elements in $\varepsilon_{t}$ and $\eta_{t}$-than observed macroeconomic variables. In this case the least squares approach puts important weight on the stochastic specification of the model, i.e. the covariance matrices of $\eta, \varepsilon$. In economic terms this implies that both the impulse response behavior of the model and the assumed variance of structural shocks will determine the plausibility of particular drivers of the economy and the actual interpretation of the data will depends on both the deterministic and stochastic parameterization. The assumption about variances is therefore key: an assumption, say, on zero variance (impossibility) of demand shocks would eliminate household preference shocks or government stimulus as plausible stories for explaining GDP growth or inflation and would result in a severly misspecified model.

Shock decompositions Having estimates of exogenous shocks and initial conditions allows us to carry out a decomposition of path of observed (and state) variables in terms of exogenous shocks, as follows from recursion on (A1)-(A2)

$$
Y_{t}=Z \sum_{\tau=0}^{t} T^{t-\tau} R \varepsilon_{\tau \mid T}+T^{\tau-t_{0}} X_{0 \mid T}+H \eta_{t}
$$

Implementation of the Kalman filter and smoother is also readily available in IRIS Toolbox for Matlab. 
Table 1. Calibration

\begin{tabular}{|c|c|c|c|}
\hline Parameter & Description & Value & Source/Remarks \\
\hline \multicolumn{4}{|c|}{ Relative Prices and their Trends } \\
\hline$w$ & Share of food in the CPI & 0.36 & Kenya National Bureau of Statistics \\
\hline$\Delta \overline{r l p}$ & Trend growth rate, relative price of food & 6.5 & Historical average \\
\hline$\theta_{r l p}$ & Persistence, Trend growth, relative price of food & 0.8 & System properties (S.P.) \\
\hline$\Delta \bar{z}$ & Trend growth rate, real exchange rate & -4 & Historical average \\
\hline$\theta_{r l p}$ & Persistence, Trend growth, real growth rate & 0.65 & S.P. \\
\hline \multicolumn{4}{|c|}{ Output and Real Interest Rates } \\
\hline $\bar{g}$ & Trend growth rate, non-Agricultural GDP & 4 & Historical average \\
\hline$\theta_{g}$ & Persistence, Trend growth, GDP & 0.5 & S.P. \\
\hline$\beta_{1}$ & Backward looking parameter, IS curve & 0.6 & Implies real economic activity \\
\hline$\beta_{2}$ & Forward looking parameter, IS curve & 0.1 & is relatively backward looking. \\
\hline$\beta_{3}$ & Output sensitivity to real monetary cond. $(r m c)$ & 0.15 & Weak interest rate channel \\
\hline$\beta_{4}$ & Weight of real exchange rate in $r m c$ & 0.6 & Strong exchange rate channel \\
\hline$\beta_{5}$ & Output sensitivity to foreign demand & 0.15 & Relatively large \\
\hline$\rho_{\overline{r r}}$ & Persistence, equilibrium real interest rate & 0.75 & S.P. \\
\hline$\overline{r r}$ & Equilibrium real interest rate & 1 & Historical average \\
\hline \multicolumn{4}{|c|}{ Non-Food Phillips Curve } \\
\hline$\lambda_{1}$ & Forward looking parameter & 0.4 & \\
\hline$\lambda_{2}$ & Exposure to imported food inflation & 0.05 & \\
\hline$\lambda_{3}$ & Sensitivity to real marginal cost $(r m c)$ & 0.2 & \\
\hline$\lambda_{4}$ & Weight of output gap in $r m c$ & 0.5 & \\
\hline \multicolumn{4}{|c|}{ Food Phillips Curve } \\
\hline$b_{1}$ & Forward looking parameter & 0.5 & \\
\hline$b_{2}$ & Exposure to imported food inflation & 0.05 & \\
\hline$b_{3}$ & Sensitivity to real marginal cost $(r m c)$ & 0.1 & \\
\hline$b_{4}$ & Weight of food real exchange rate gap in $r m c$ & 0.1 & \\
\hline$b_{5}$ & Weight of food deviation gap in $r m c$ & 0.7 & \\
\hline
\end{tabular}


Table 2. Calibration (continued)

\begin{tabular}{|c|c|c|c|}
\hline Parameter & Description & Value & Source/Remarks \\
\hline \multicolumn{4}{|c|}{ Monetary Policy and Uncovered Interest Parity } \\
\hline$\rho_{\text {prem }}$ & AR parameter for country risk premium & 0.75 & S.P. \\
\hline$\phi$ & Forward-looking term in UIP & 0.85 & $\ldots$ \\
\hline$\gamma_{1}$ & Interest rate smoothing in MP rule & 0.8 & $\ldots$ \\
\hline$\gamma_{2}$ & Long-run MP response to inflation & 1.4 & $\ldots$ \\
\hline$\gamma_{3}$ & Long-run MP response to output gap & 0 & $\ldots$ \\
\hline$\gamma_{4}$ & Long-run MP response to nominal depreciation & 0.25 & $\ldots$ \\
\hline $\bar{\pi}$ & Inflation target & 5 & $\ldots$ \\
\hline$\rho_{\bar{\pi}}$ & Persistence, inflation target & 0.85 & $\ldots$ \\
\hline \multicolumn{4}{|c|}{ Rest of the World } \\
\hline$\Delta \overline{r l p}^{*}$ & Trend growth rate, intl. relative price of food & 2 & Historical average \\
\hline$\theta_{r l p^{*}}$ & Persistence, Trend growth, intl. relative price of food & 0.5 & S.P. \\
\hline$\beta_{1}^{*}$ & Backward looking parameter, IS curve & 0.5 & $\ldots$ \\
\hline$\beta_{2}^{*}$ & Forward looking parameter, IS curve & 0.5 & $\ldots$ \\
\hline$\beta_{3}^{*}$ & Output gap sensitivity to real interest rate gap & 0.05 & $\ldots$ \\
\hline$\lambda_{1}^{*}$ & Forward looking parameter, Phillips curve & 0.6 & \\
\hline$\lambda_{2}^{*}$ & Sensitivity to output gap, Phillips curve & 0.06 & \\
\hline$\gamma_{1}^{*}$ & Interest rate smoothing in MP rule & 0.75 & $\ldots$ \\
\hline$\gamma_{2}^{*}$ & Long-run MP response to inflation & 1.7 & $\ldots$ \\
\hline$\gamma_{3}^{*}$ & Long-run MP response to output gap & 0.25 & $\ldots$ \\
\hline$\rho_{p_{f}^{*}}$ & Persistence, international food price gap & 0.75 & S.P. \\
\hline$\rho_{\overline{r r} *}^{*}$ & Persistence, equilibrium real interest rate & 0.5 & S.P. \\
\hline$\overline{r r}^{*}$ & Equilibrium real interest rate & 2.5 & Historical average \\
\hline
\end{tabular}


Table 3. Calibration (continued)

\begin{tabular}{cccc}
\hline Parameter & Description & Value & Source/Remarks \\
\hline$\sigma_{\overline{r l p}}$ & Monetary Policy and Uncovered Interest Parity & \\
$\sigma_{\bar{z}}$ & Volatility, dom. relative food price trend & 2 & S.P. \\
$\sigma_{\bar{y}}$ & Volatility, real exchange rate trend shocks & 3 & S.P. \\
$\sigma_{\bar{g}}$ & Volatility, potential output growth shocks & 1.5 & S.P. \\
$\sigma_{y g a p}$ & Volatility, potential output drift shocks & 1 & S.P. \\
$\sigma_{\overline{r r}}$ & Volatility, output gap shocks & 1 & S.P. \\
$\sigma_{\pi_{n f}}$ & Volatility, equilibrium real interest rate shocks & 0.7 & S.P. \\
$\sigma_{\pi_{n f}}$ & Volatility, dom. non-food shocks & 1.5 & S.P. \\
$\sigma_{s}$ & Volatility, dom. food shocks & 2.5 & S.P. \\
$\sigma_{p r e m}$ & Volatility, UIP shocks & 3.5 & S.P. \\
$\sigma_{r s}$ & Volatility, risk premium shocks & 3.5 & S.P. \\
$\sigma_{\bar{\pi}}$ & Volatility, monetary policy shocks & 1.5 & S.P. \\
$\sigma_{y g a p^{*}}$ & Volatility, inflation targets & 1 & S.P. \\
$\sigma_{r s^{*}}$ & Volatility, US output gap shocks & 0.3 & S.P. \\
$\sigma_{\overline{r r} *}$ & Volatility, US monetary policy shocks & 0.3 & S.P. \\
$\sigma_{\pi^{*}}$ & Volatility, US equilibrium real interest rate shocks & 0.08 & S.P. \\
$\sigma_{\overline{r l p} *}$ & Volatility, US CPI shocks & 1.5 & S.P. \\
$\sigma_{r l p g a p^{*}}$ & Volatility, intl. relative food price trend shocks & 0.35 & S.P. \\
\hline & Volatility, intl. relative food price gap shocks & 0.3 & S.P. \\
\hline
\end{tabular}


Table 4. In-sample model forecasts (MF) vs. random walk (RW), RMSE ratios $\left(\frac{R M S E_{M F}}{R M S E_{R W}}\right)$

\begin{tabular}{lllllllll}
\hline & $\mathbf{q 1}$ & $\mathbf{q 2}$ & $\mathbf{q 3}$ & $\mathbf{q 4}$ & $\mathbf{q 5}$ & $\mathbf{q 6}$ & $\mathbf{q 7}$ & $\mathbf{q 8}$ \\
\hline Nominal Repo Rate (per cent p.a.) & 0.38 & 0.45 & 0.43 & 0.55 & 0.55 & 0.53 & 0.53 & 0.56 \\
YoY CPI Inflation (per cent) & 0.69 & 0.84 & 0.80 & 0.76 & 0.72 & 0.66 & 0.63 & 0.61 \\
Nominal Exch. Rate (KES per USD) & 0.44 & 0.51 & 0.49 & 0.50 & 0.50 & 0.48 & 0.47 & 0.47 \\
Output Gap (per cent) & 0.64 & 0.57 & 0.61 & 0.72 & 0.84 & 0.96 & 0.96 & 0.94 \\
\hline
\end{tabular}


Figure 1: Food and Non-food Inflation, Kenya.

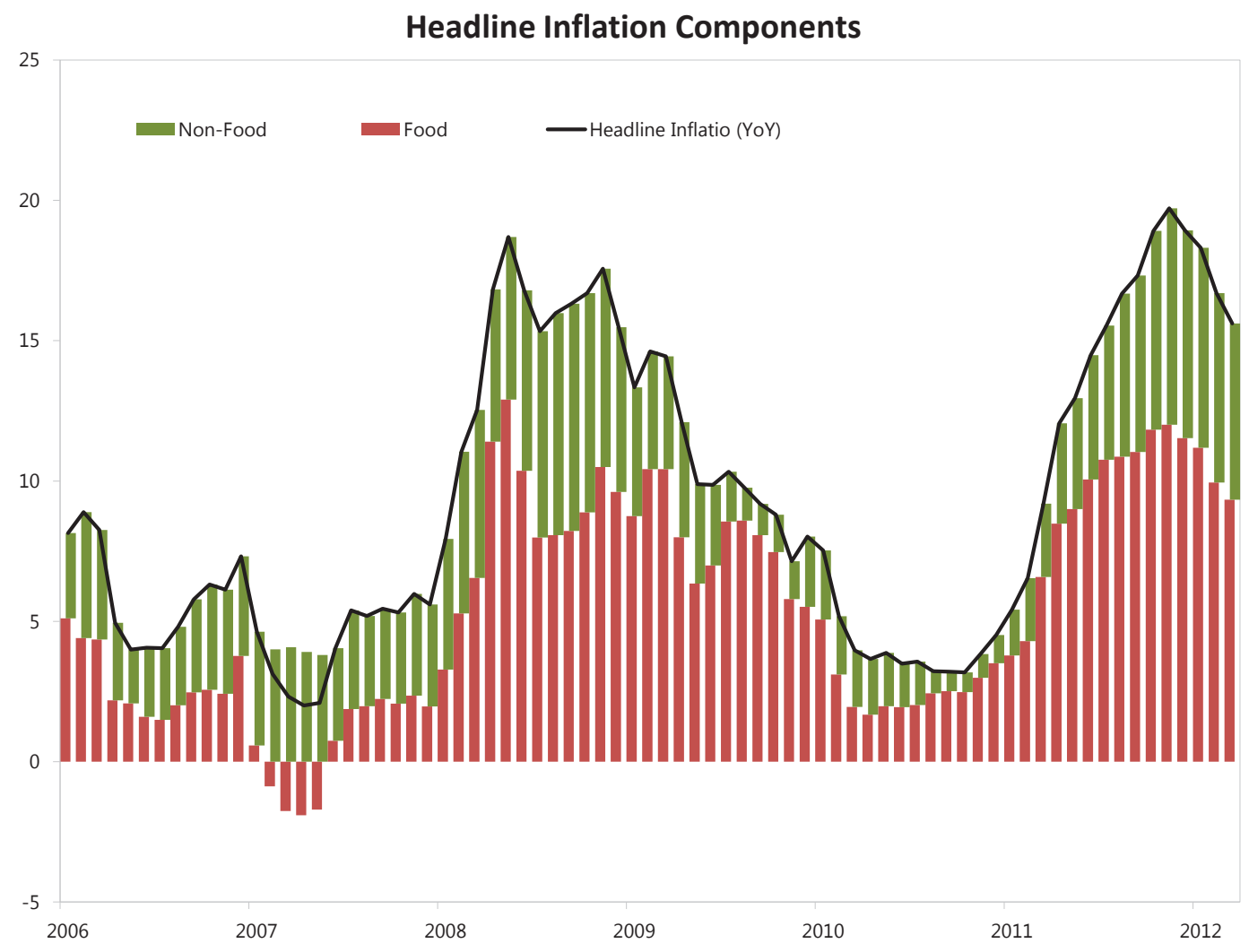


Figure 2: Domestic and International Food Prices (in US\$).

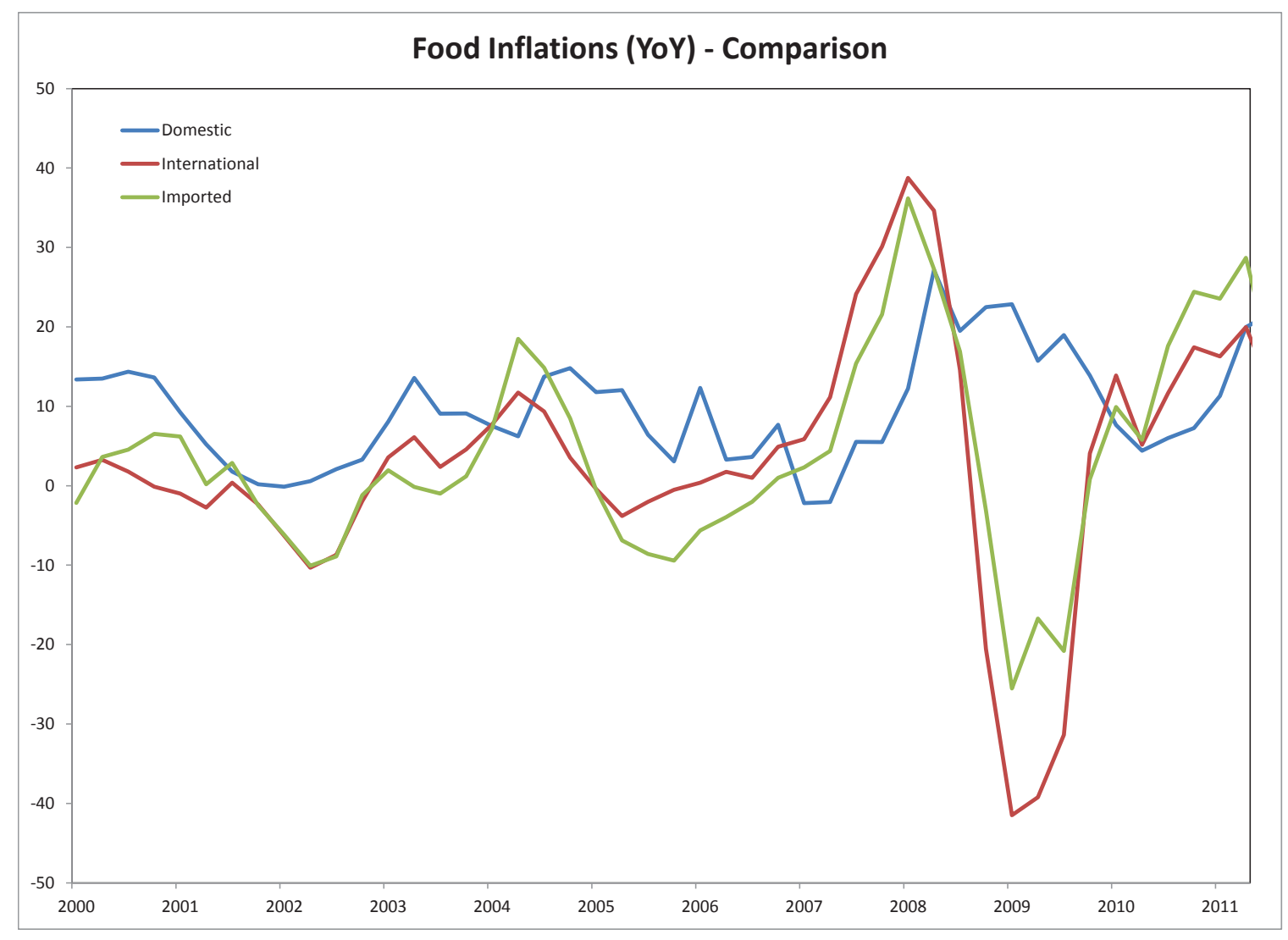


Figure 3: Short Term Interest Rates, Kenya.

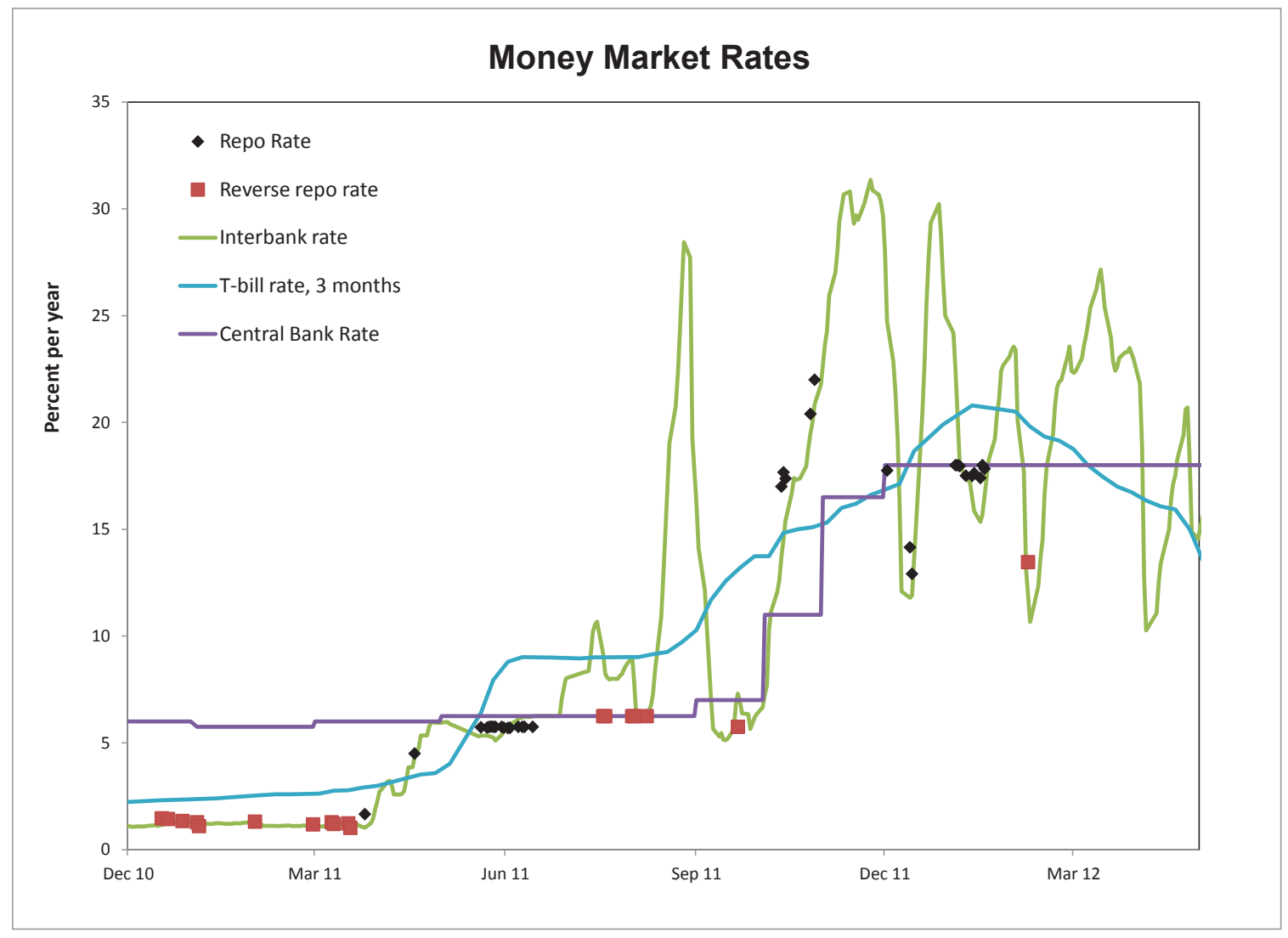

(C)International Monetary Fund. Not for Redistribution 
Figure 4: Impulse Response Functions, $\epsilon_{t}^{r l p g a p^{*}}=1$
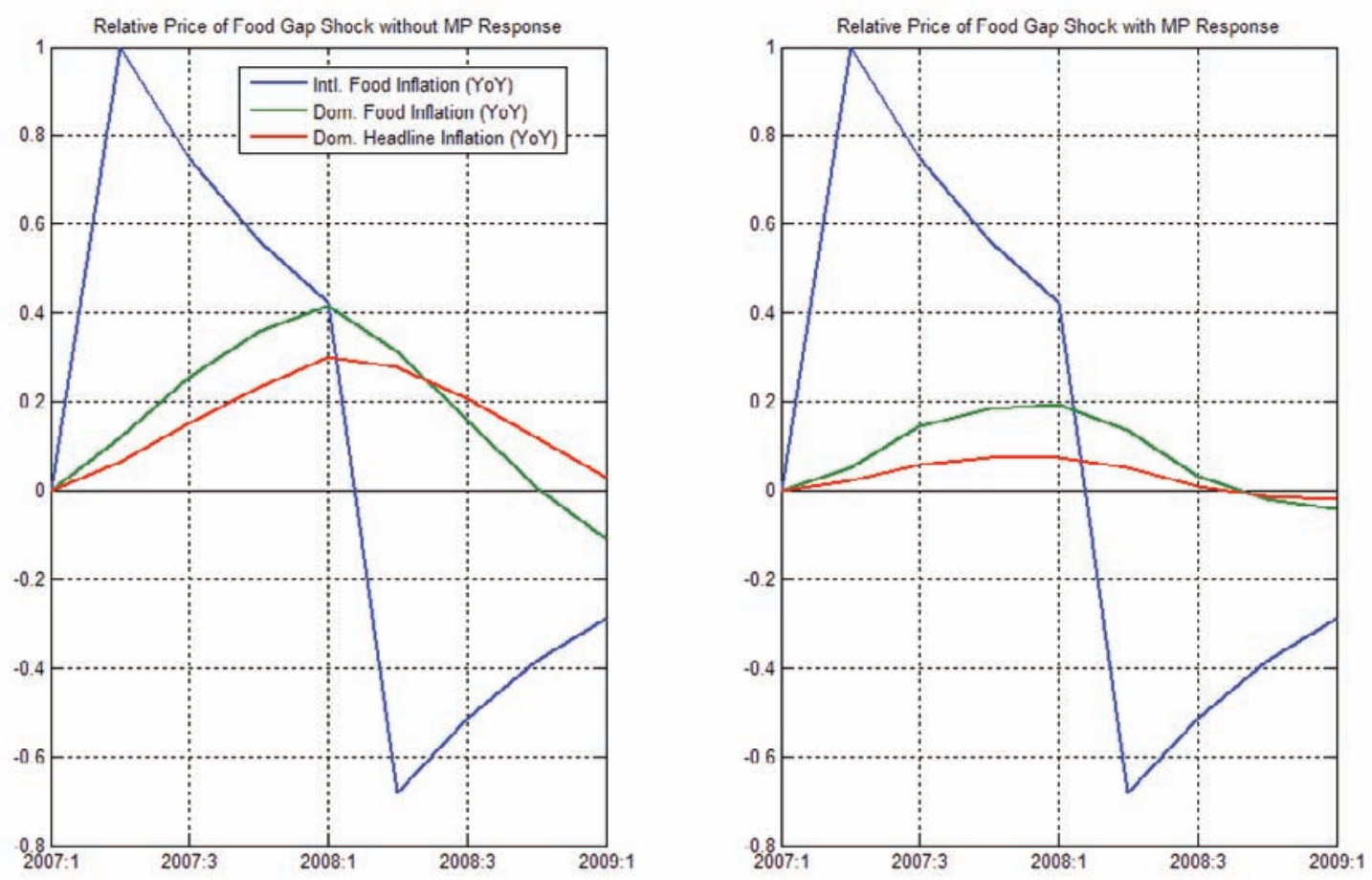
Figure 5: Impulse Response Functions, $\epsilon_{t}^{R S}=1$

Monetary Policy Shock
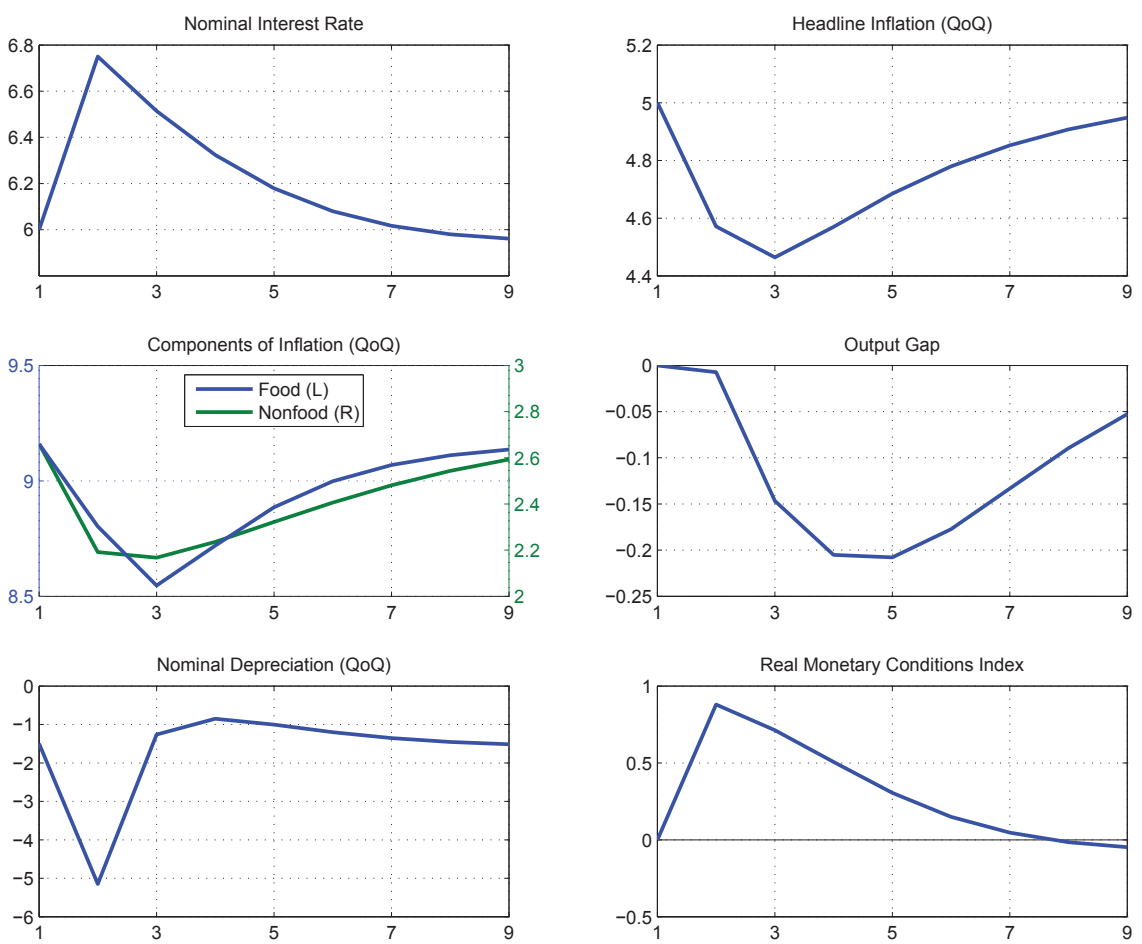
Figure 6: Impulse Response Functions, $\epsilon_{t}^{\overline{r l p}^{*}}=1$

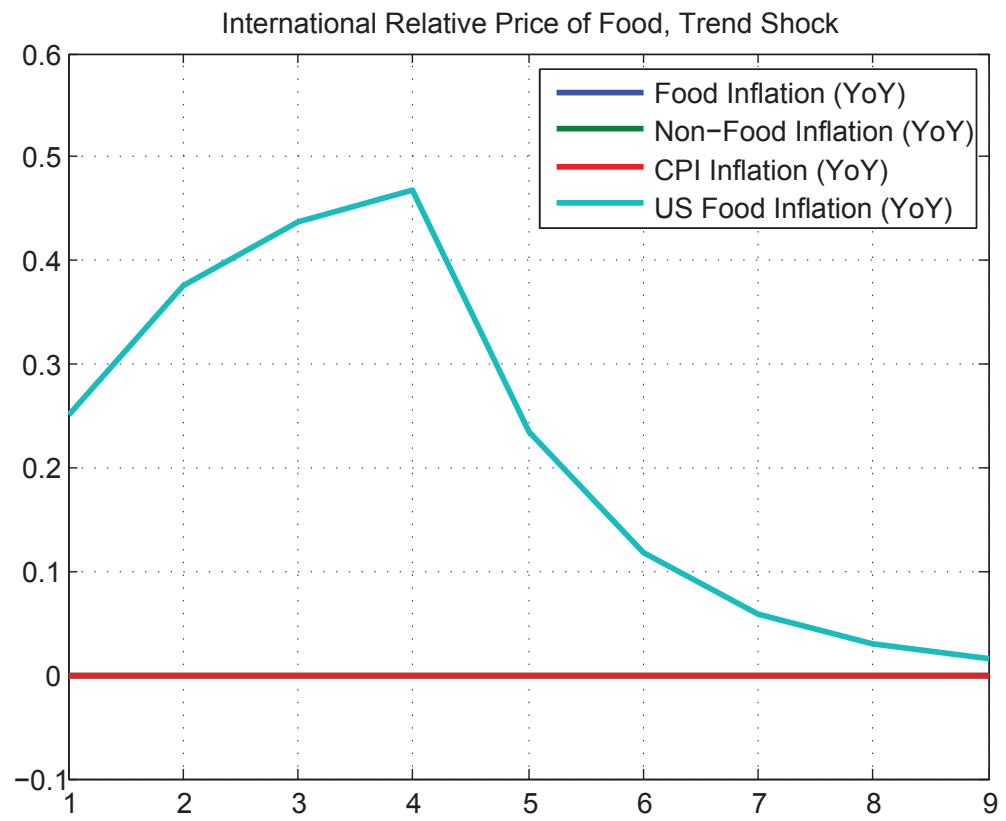


Figure 7: Impulse Response Functions, $\epsilon_{t}^{\overline{r l p}}=1$

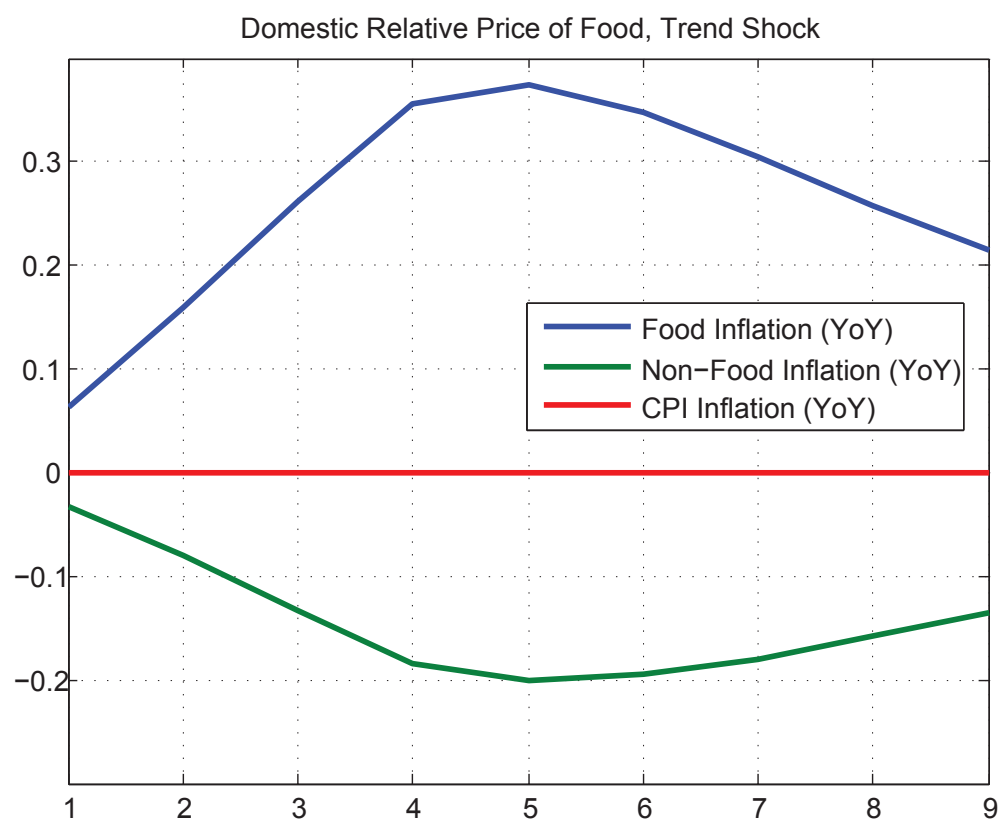


Figure 8: Trend/Gap Decomposition, Relative Prices

Real Ex. Rate

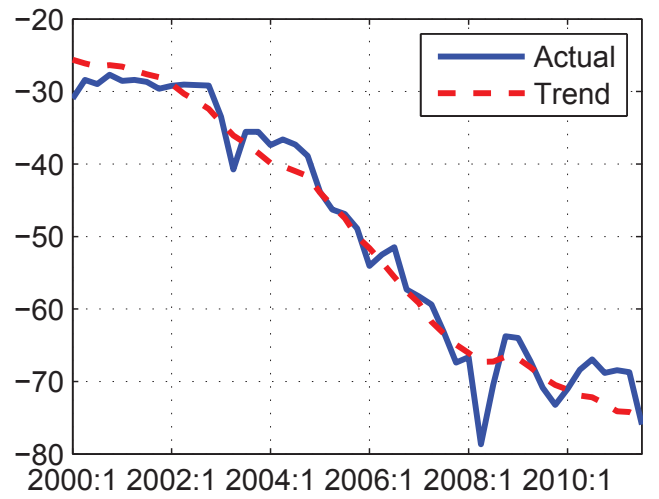

2000:1 2002:1 2004:1 2006:1 2008:1 2010:1

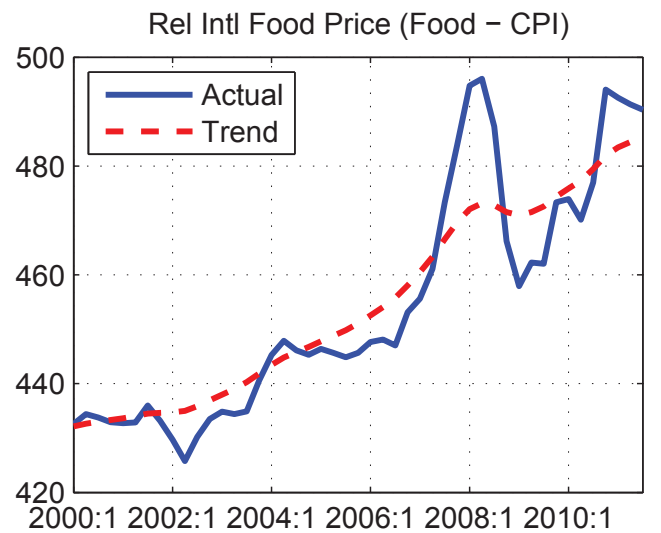

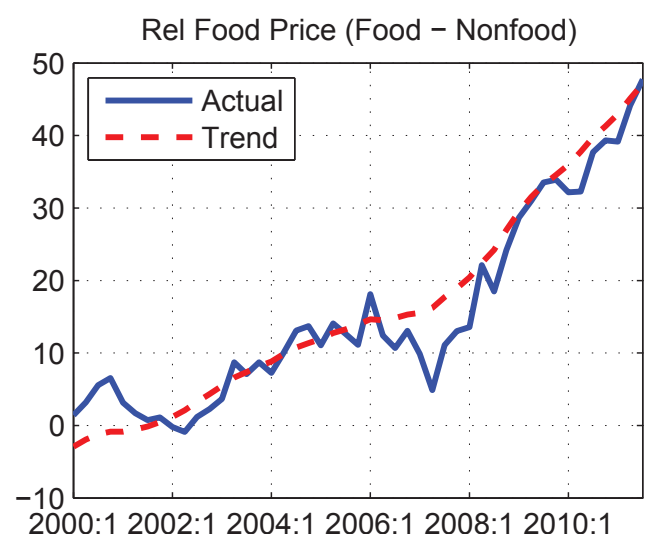

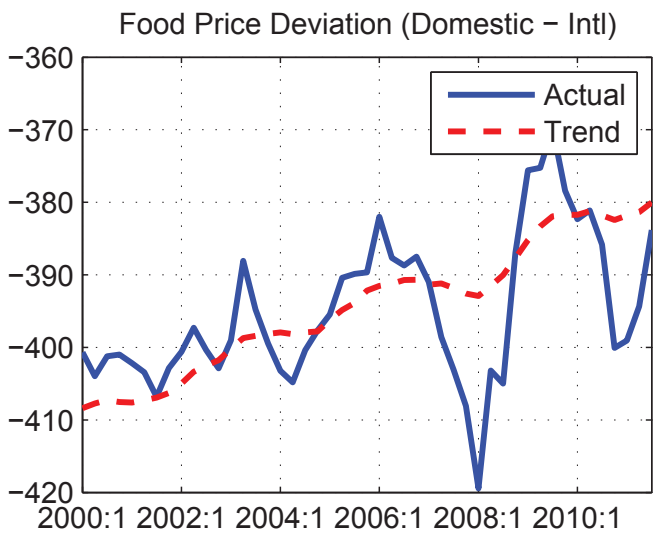


Figure 9: Trend/Gap Decomposition, GDP

\section{Output Level/Tnd}

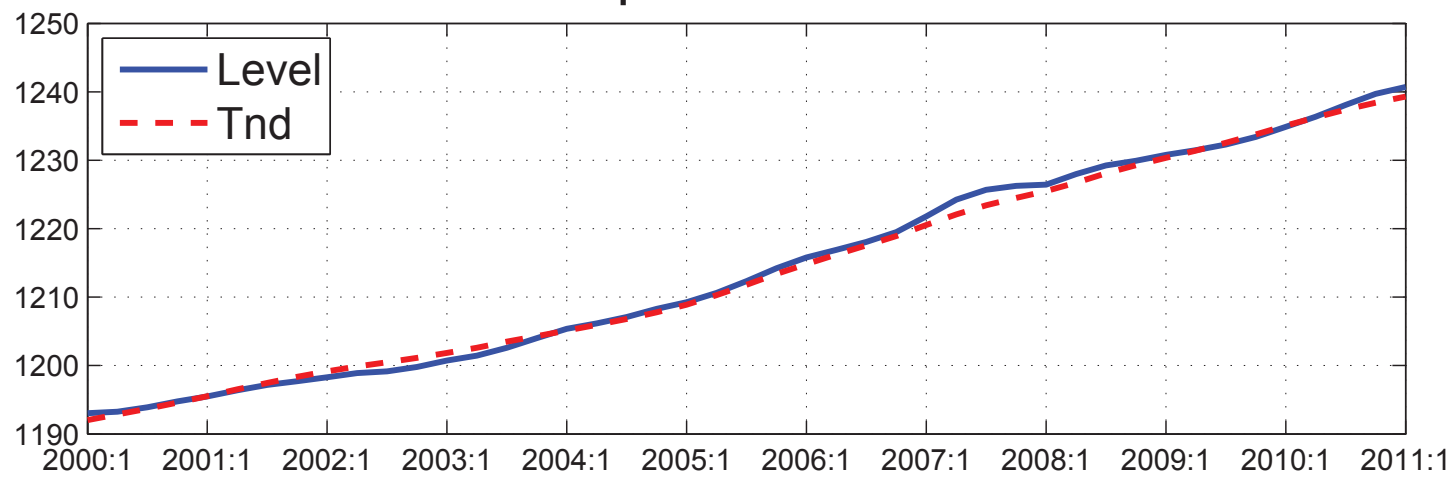

\section{Output Gap}

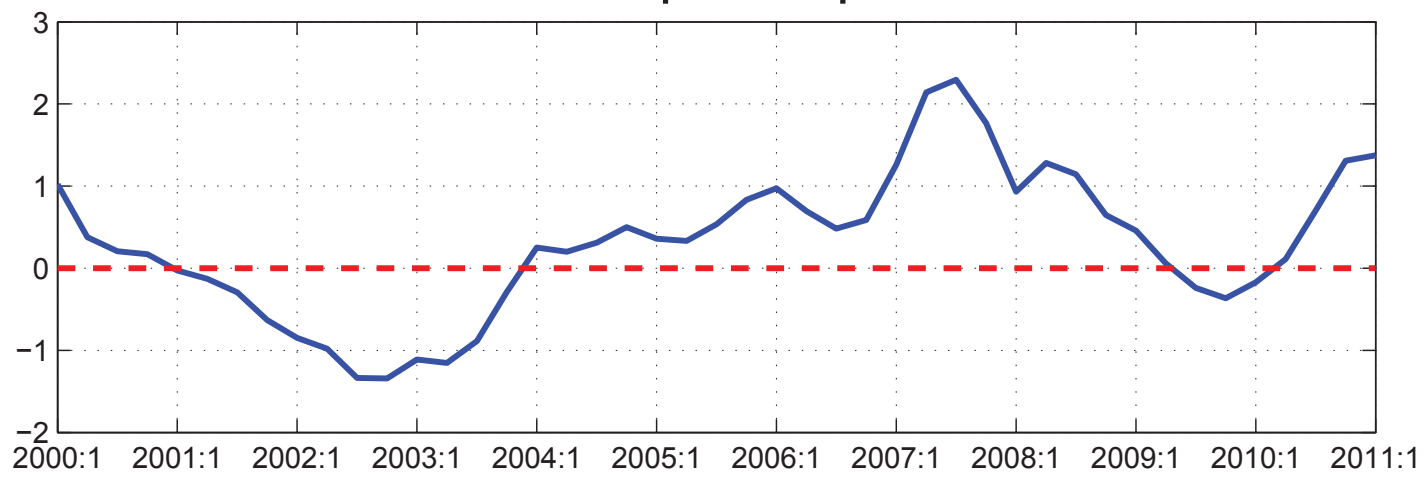


Figure 10: Trend/Gap Decomposition, Real Interest Rates

Real Int. Rate Level/Tnd

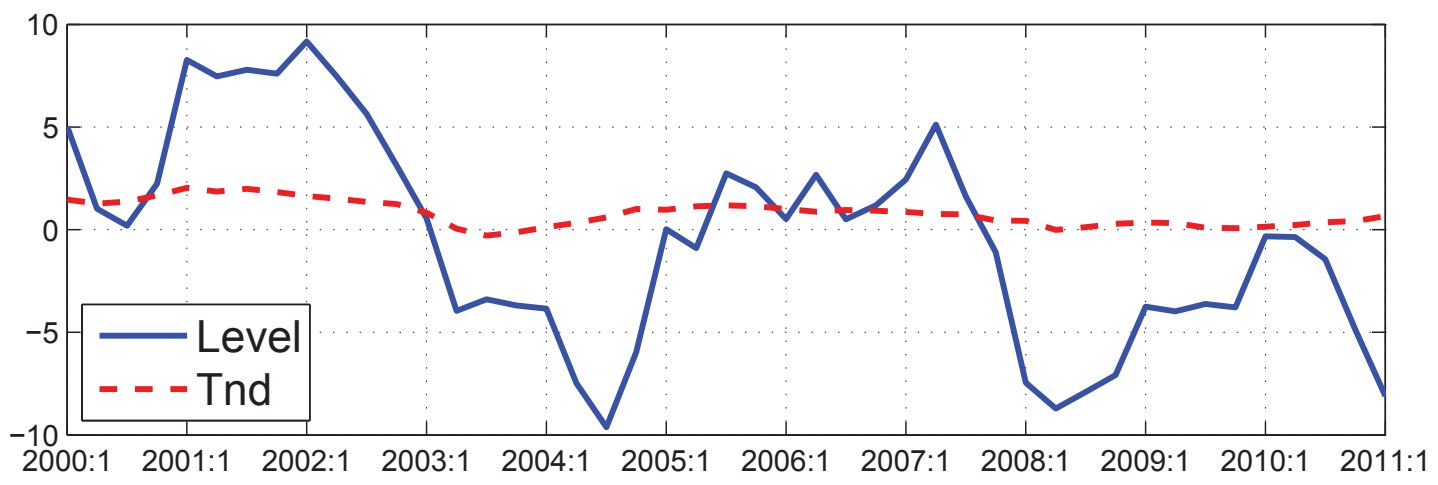

Real Int. Rate Gap

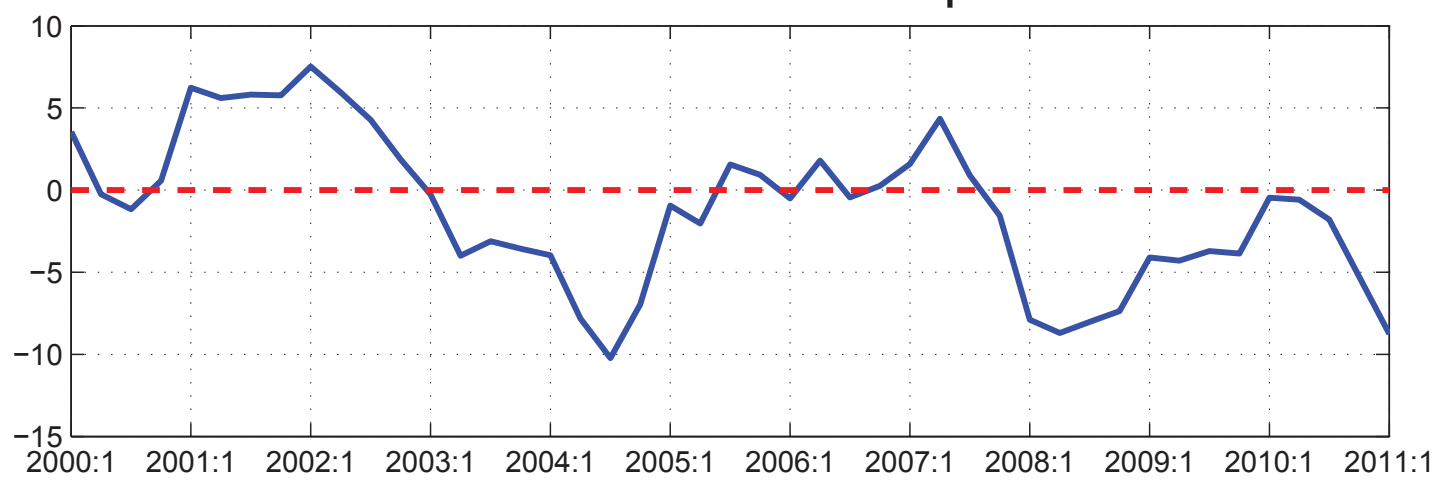


Figure 11: Shock Decomposition, Output Gap

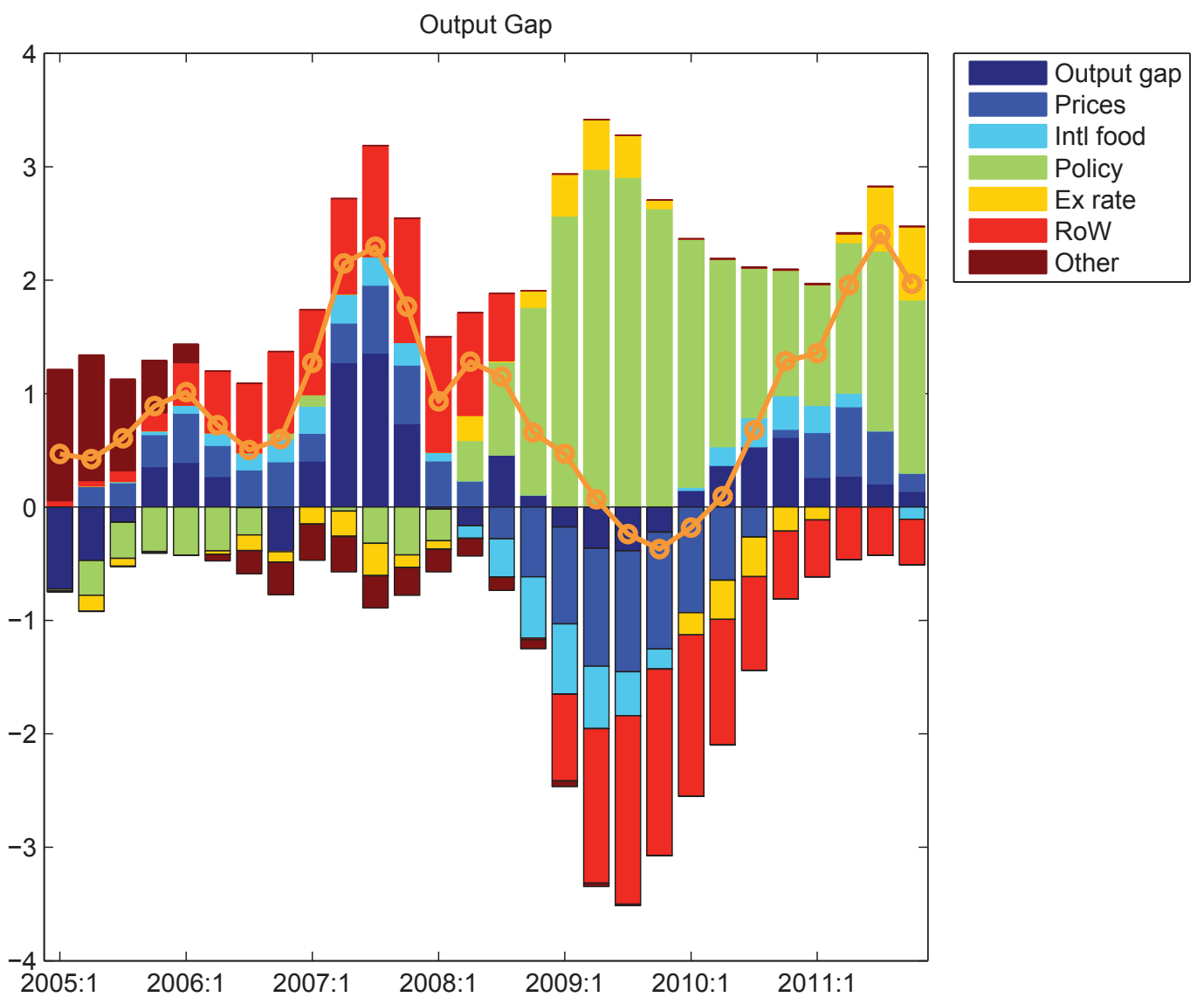


Figure 12: Shock Decomposition, Non-Food Inflation

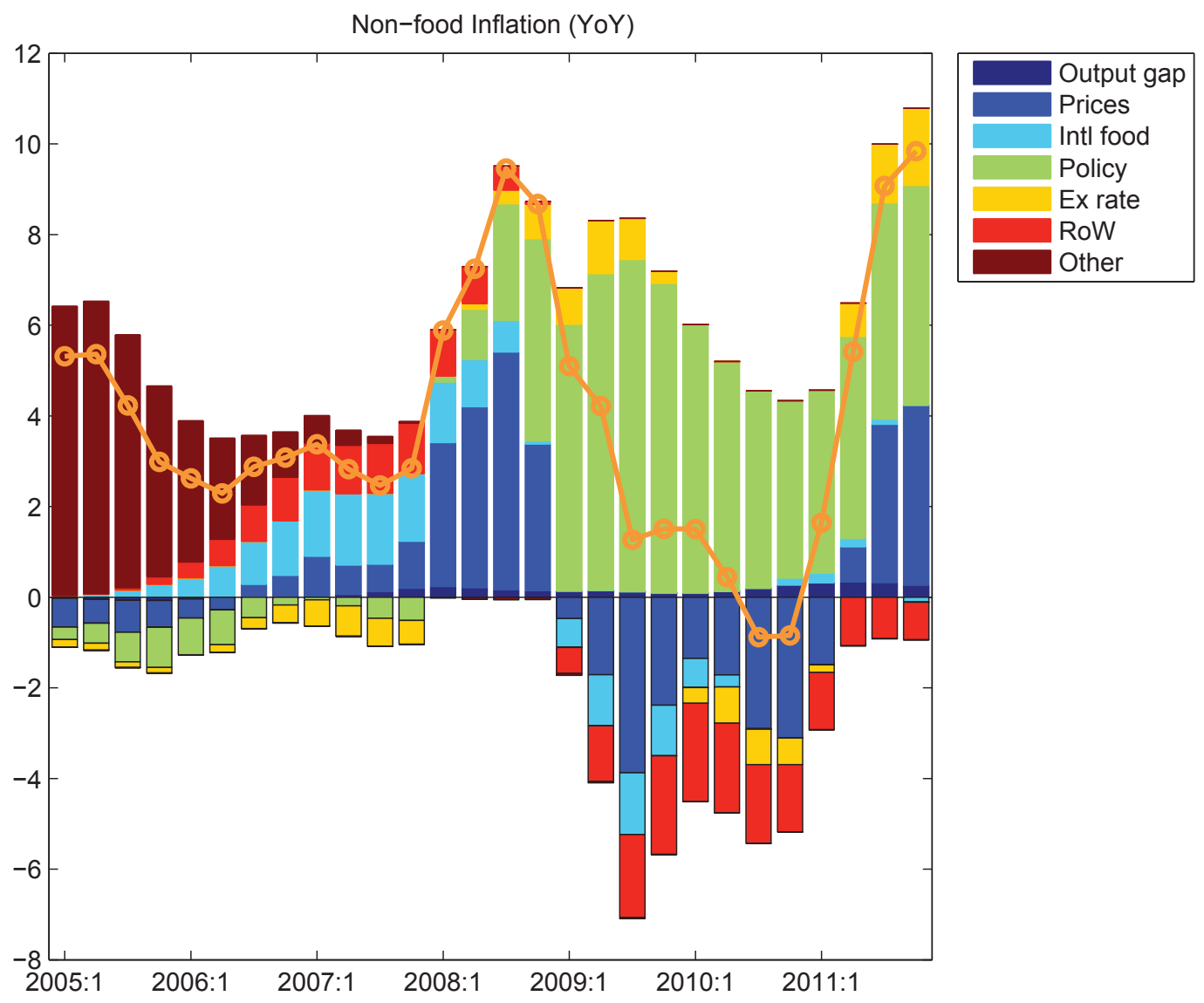


Figure 13: Shock Decomposition, Food Inflation

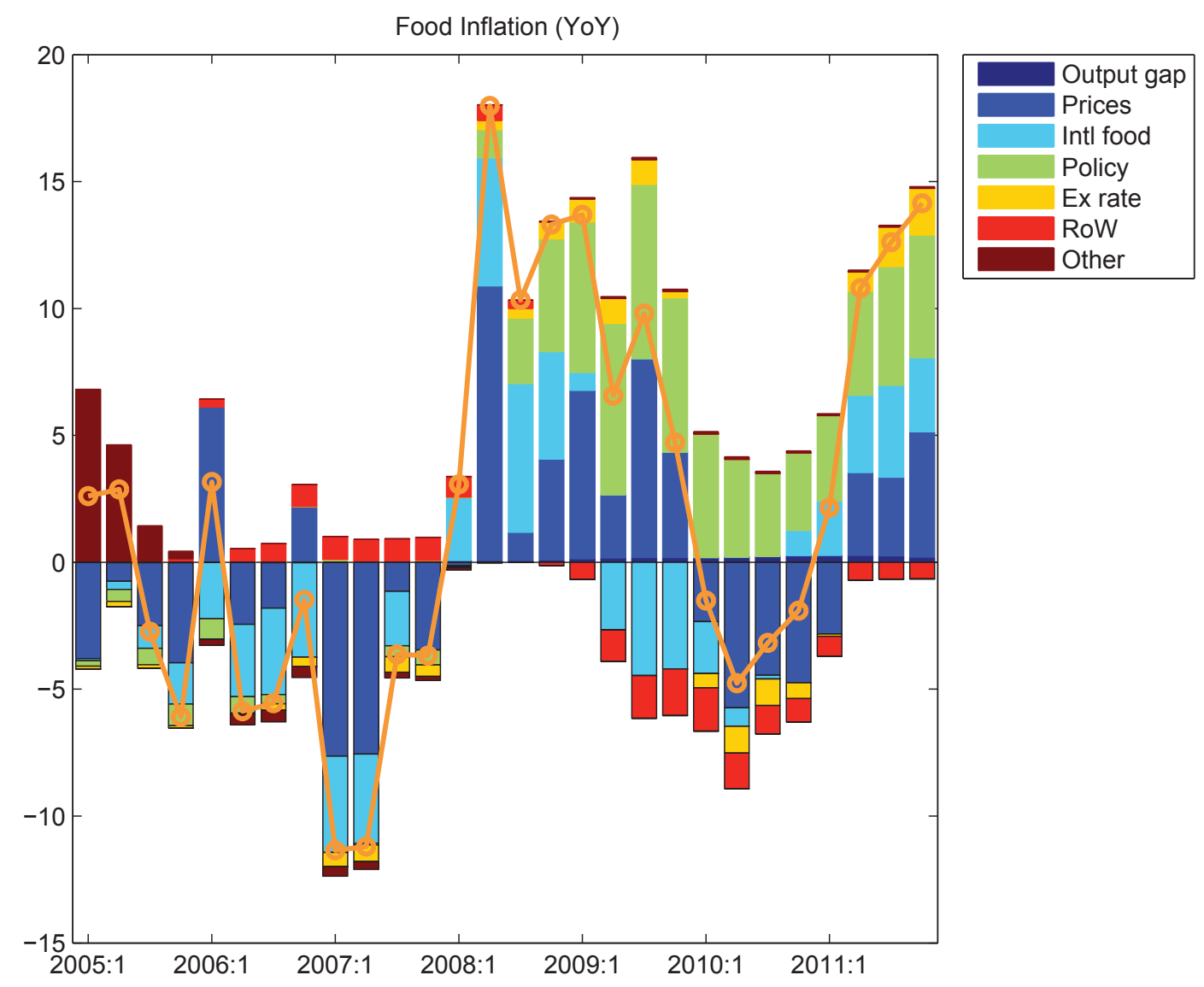


Figure 14: Shock Decomposition, Headline Inflation

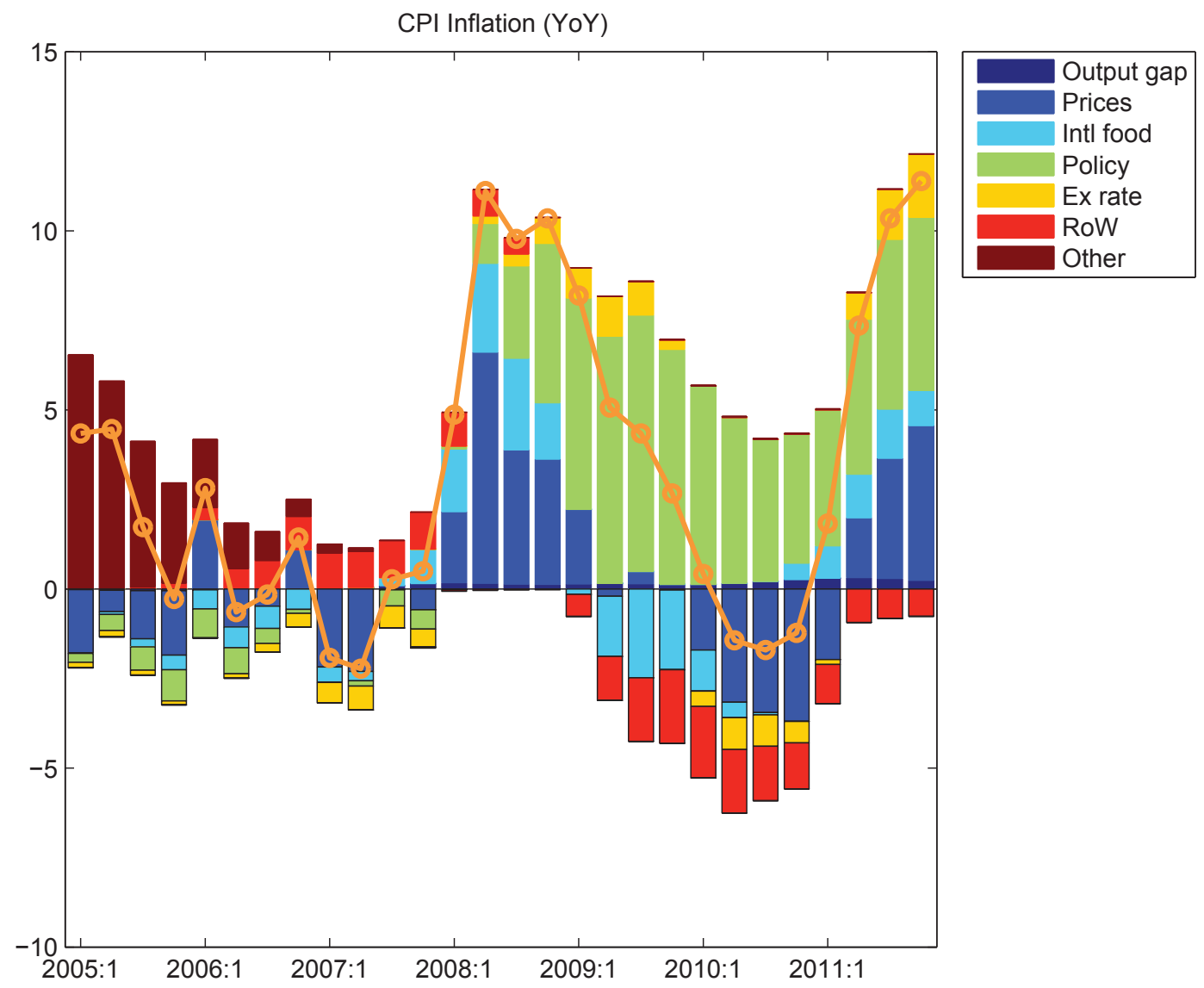


Figure 15: Shock Decomposition, Nominal Depreciation

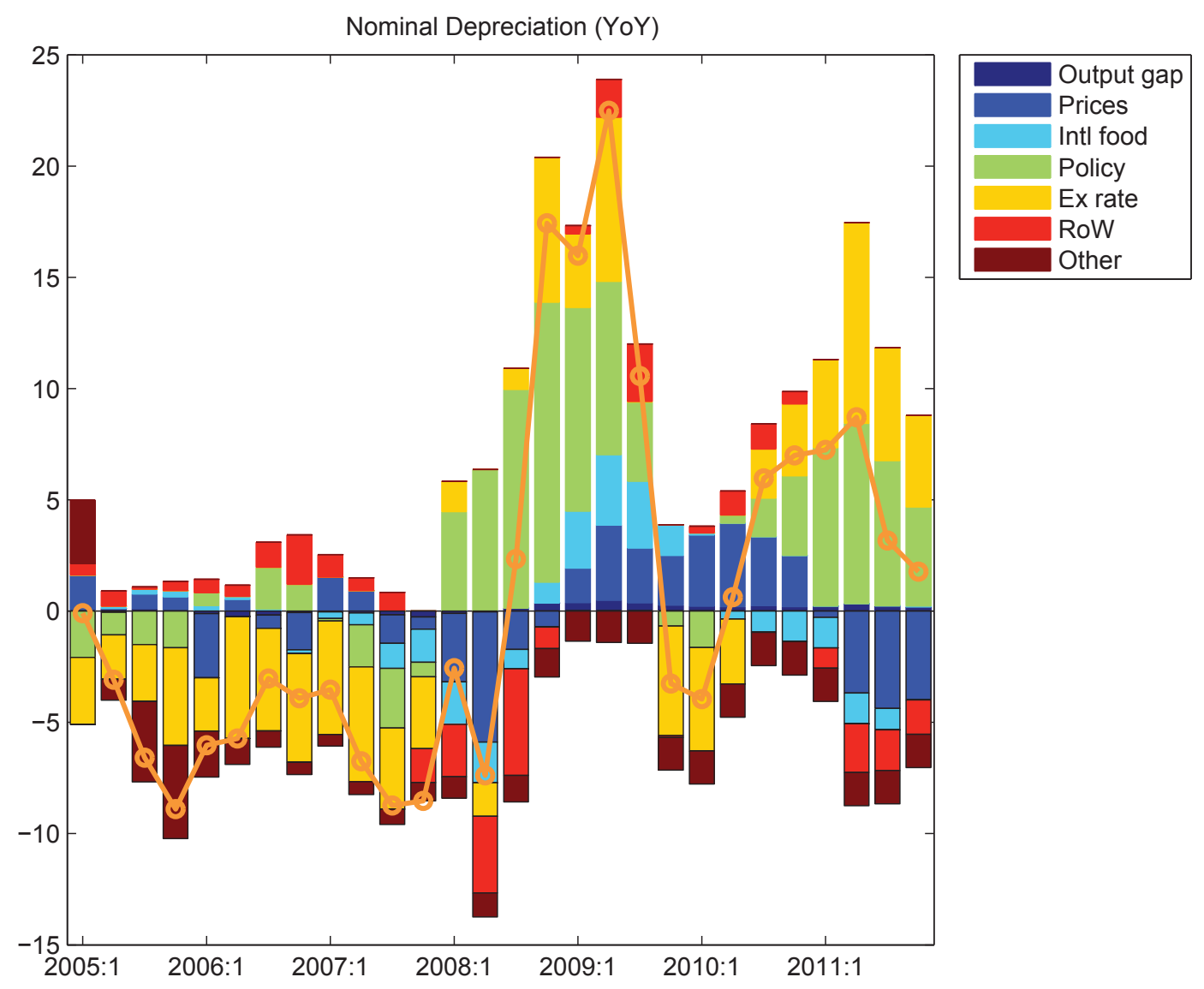


Figure 16: Real Marginal Costs Decomposition - Food Price Inflation
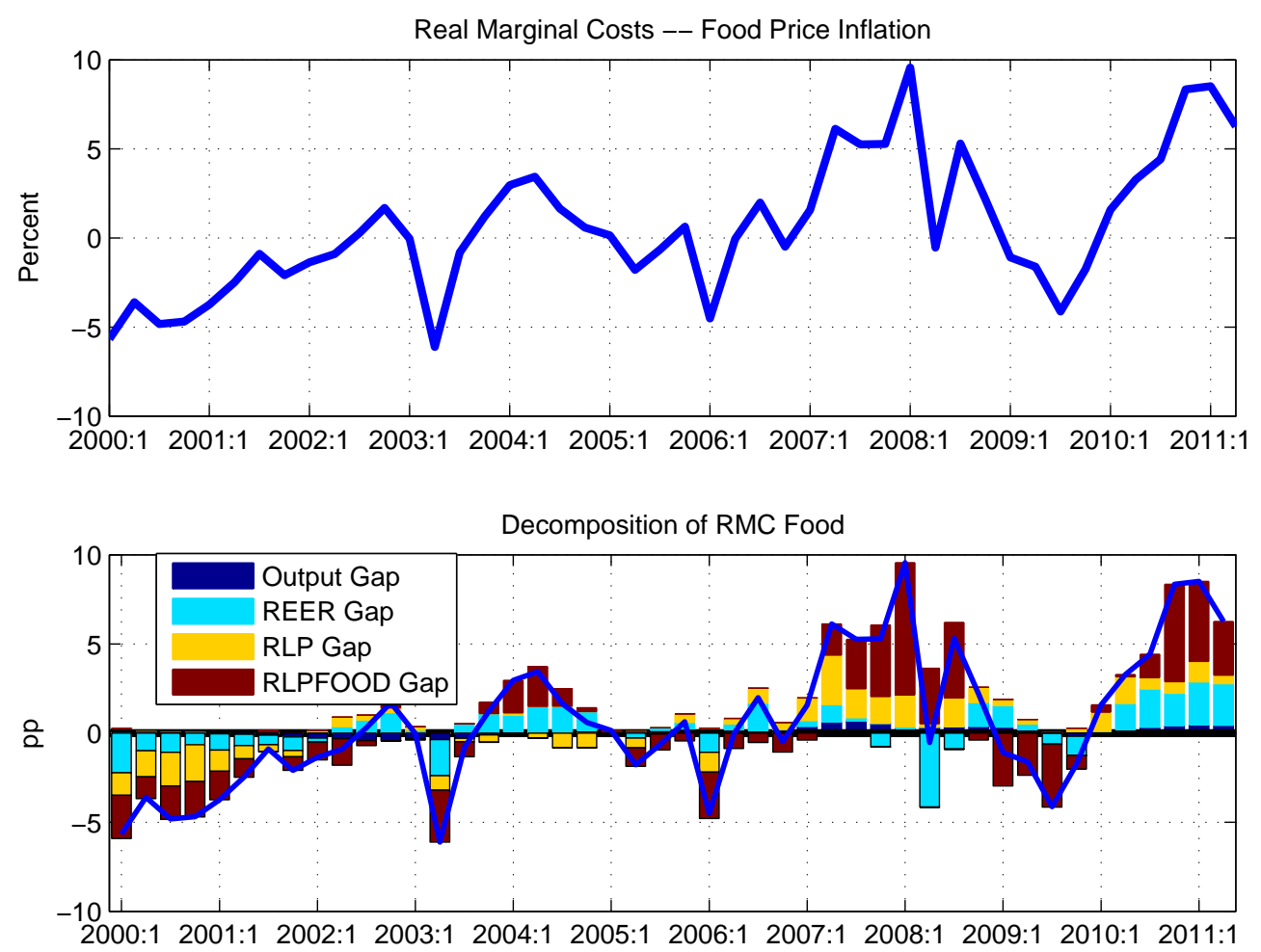
Figure 17: Central Bank Rate - Repo Rates
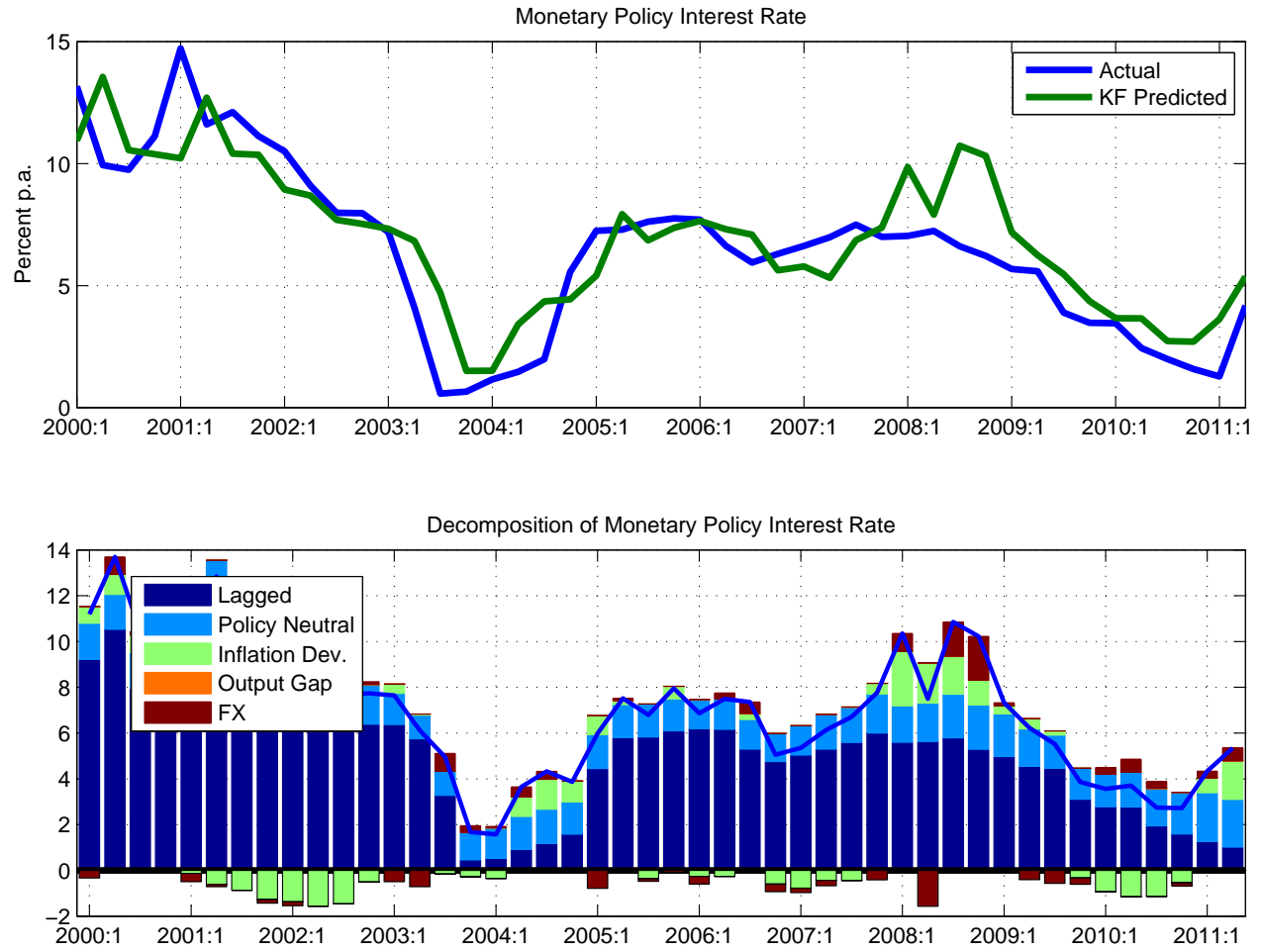
Figure 18: Impulse Response Functions, 2007-2008 Global Food Crisis.
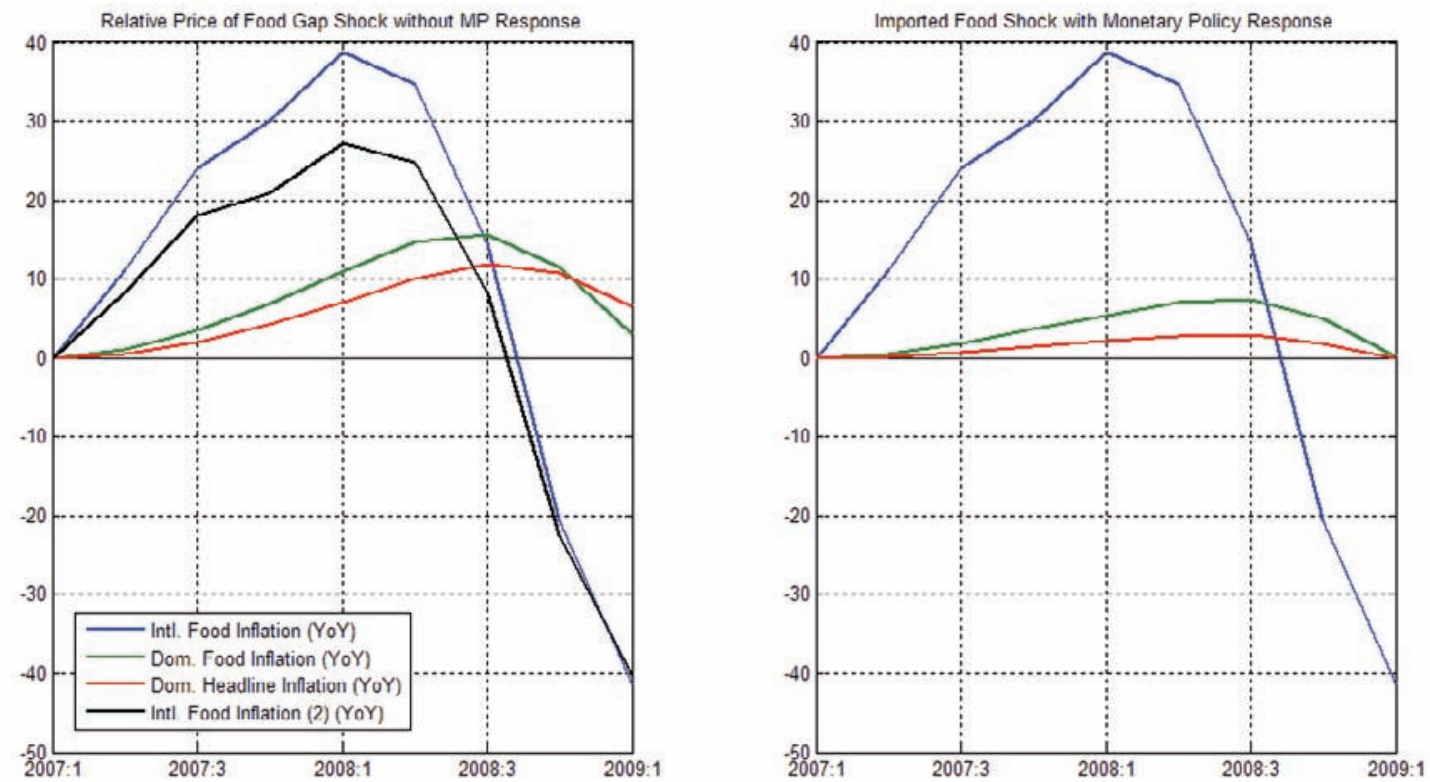
Figure 19: Conditioned historical simulations, Selected Variables
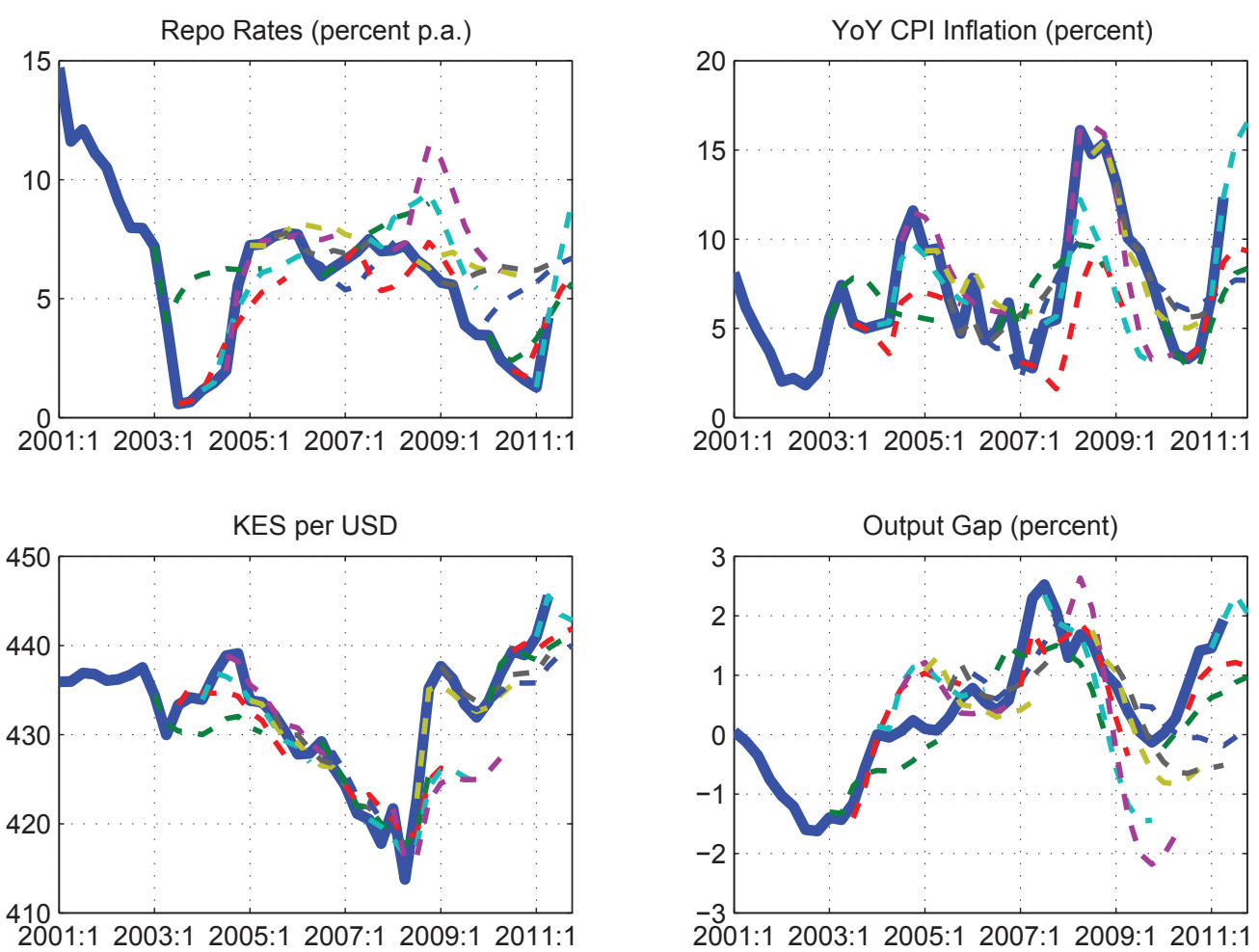
Figure 20: Model Forecast versus Actual Data
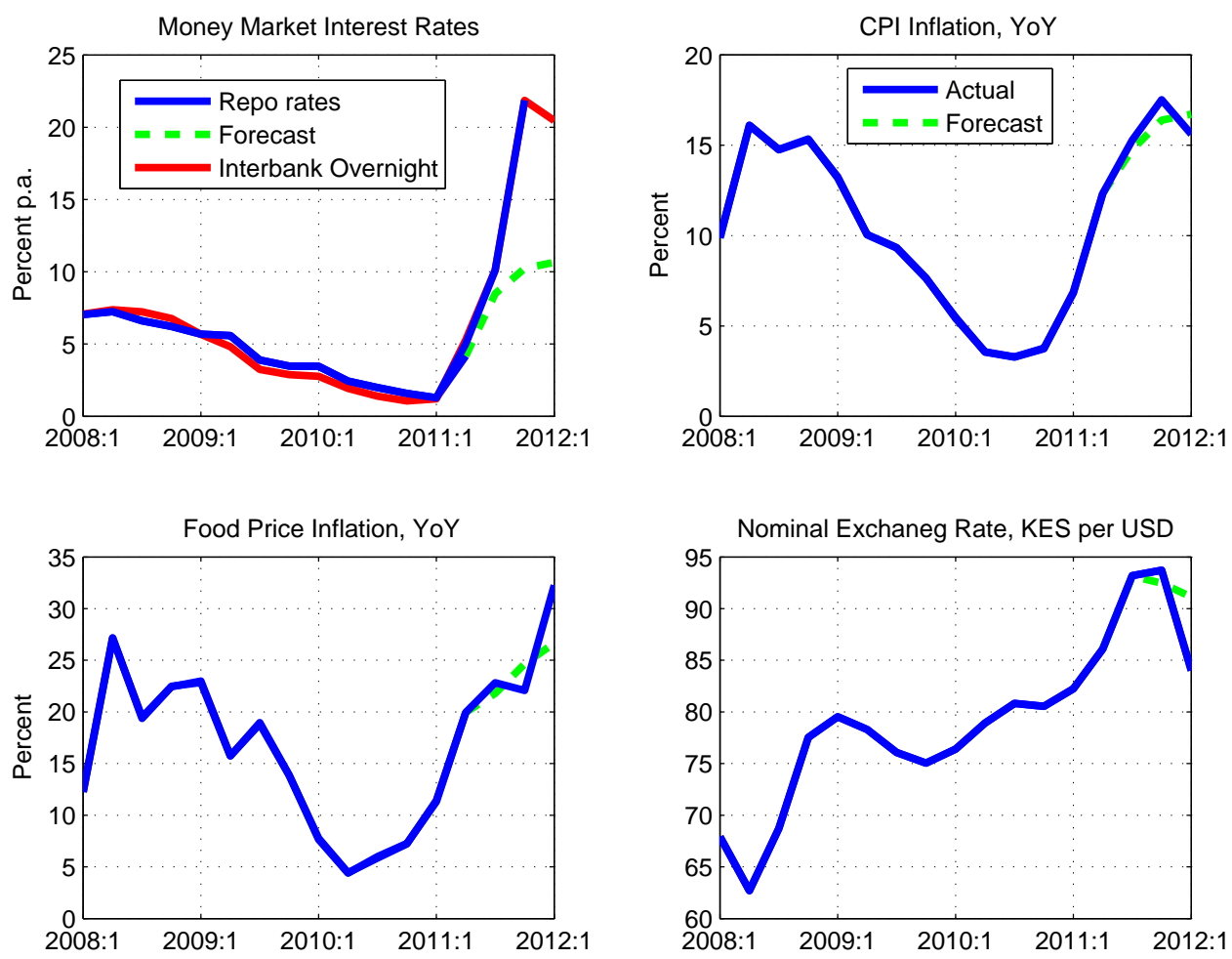